\title{
Numerical Simulation of Pipeline-Pavement Damage Caused by Explosion of Leakage Gas in Buried PE Pipelines
}

\author{
Yang Zhuohua, Ye Qing (D), Jia Zhenzhen, and Li He \\ School of Resource, Environment and Safety Engineering, Hunan University of Science and Technology, Xiangtan 411100, China \\ Correspondence should be addressed to Ye Qing; cumtyeqing@126.com
}

Received 12 December 2019; Revised 29 August 2020; Accepted 3 September 2020; Published 15 September 2020

Academic Editor: Giosuè Boscato

Copyright (c) 2020 Yang Zhuohua et al. This is an open access article distributed under the Creative Commons Attribution License, which permits unrestricted use, distribution, and reproduction in any medium, provided the original work is properly cited.

\begin{abstract}
In order to investigate the damage influence of the leakage explosion in urban gas pipeline on the surrounding environment, the numerical models of buried PE (polyethylene) pipes under urban pavement were established by using ANSYS/LS-DYNA in this study. The reliability of the numerical models was verified on the basis of the explosion experiments. According to the amount of gas leakage, the TNT explosive equivalent was determined. The gas leakage explosion process of buried PE pipes was studied, and the pressure and stress changes of pipes and pavements under different explosive equivalents and buried depths were analyzed; at last, the deformation law of pipes and pavements were discussed. The results show that the PE pipes are fractured during the leakage explosion and a spherical explosion cavity is formed in the soil. The pavement above the explosion point bulges upward and forms a circle. The maximum pressure of pipe near the explosion point increases linearly with the increase of explosive equivalent, and a proportional relation is observed between the fracture width of pipe and the explosive equivalent. The degree and duration of pavement deformation increase significantly with the increase of explosive equivalents. The dynamic response of the pipes is rarely affected by the buried depth, and the change of maximum effective stress is no more than $7 \%$. However, the buried depth is of great influence on the damage degree of pavement. When the buried depth increases from $0.9 \mathrm{~m}$ to $1.5 \mathrm{~m}$, the pavement deformation can be reduced effectively. The variation rule of pavement deformation is similar to the change rule of maximum overpressure and effective plastic stress; they change in the form of concave functions with the increase of buried depth. The results can provide theoretical basis for municipal pipeline construction design and urban safety planning and provide references for the risk assessment of gas explosion in buried pipelines.
\end{abstract}

\section{Introduction}

With the rapid development of the natural gas industry and urbanization, the laying distance of urban gas pipeline has increased greatly, the length of China's urban natural gas pipeline increased by about 480,000 kilometers from 2009 to 2019. For better utilization of urban underground space and reducing risks, urban natural gas pipelines are often laid underground. However, accidents often occur in buried natural gas pipelines due to external interferences, chemical corrosion, defects, or traffic loads. The common types of pipeline accidents are leakage, fire, explosion, and poisoning choke, and the source of pipeline accidents is leakage accident [1-7]. The external disturbance is the primary cause of pipeline deformation and leakage [8]. In order to study the mechanical response of the pipeline under external disturbance, numerical simulations and experimental researches were conducted on the deformation and dynamic response of the steel pipe or PE pipeline under deflection loads, excavation loads, or other loads [9-13].Explosive loading poses a greater threat to the pipeline than other external loads. Zhang et al. [14] simulated the buckling response of steel pipes in soil or rock formations subjected to ground explosive loading, the pipes in rock formation were more susceptible to damage, and the effects of explosive equivalent, explosion height, pipe diameter-thickness ratio, buried depth, and explosion location on the buckling response of the pipes were discussed. Mokhtari and Nia [15] investigated the dynamic response of X65 steel pipe under underground explosive loading by numerical simulation. Compared with the pipeline thickness parameter, pipeline transportation pressure has a greater influence on the pipe 
deformation. Wang et al. [16] conducted numerical simulations on the dynamic response of submarine pipelines under blast loading; compared to semiburied pipelines, the laying sea bed pipelines and shallowly buried pipelines deform smaller, and the dynamic response of pipelines can be reduced by increasing the buried depth. Based on the strong explosion theory and analytical equations, Bang et al. [17] analyzed the pressure and velocity on the nearby pipes under explosive loading of hydrogen tank. The bending amplitudes of the pipes under different explosive equivalents were discussed, and the safety distance between the hydrogen tank and the pipeline was estimated. These studies provide good references for pipeline selection and laying.

After the leakage occurs, the natural gas gradually diffuses to the ground, forming a gas cloud with a certain concentration gradient. In case of an open flame, the fire and explosion may occur. According to an analysis of 1063 accidents about onshore gas pipeline leakage, explosion accidents account for about $12 \%$ of gas pipeline leakage accidents, and the occurrence probability of which was second only to fire and steam cloud accidents [18]. Leakage explosion accidents are often catastrophic, easy to cause great property losses and casualties. For example, on March 12, 2014, a natural gas pipeline leaked and exploded in Manhattan, New York, killing 8 people and injuring at least 70 others, and 2 large buildings collapsed. On August 1, 2019, a gas pipeline explosion accident occurred in Lincoln County, Kentucky, USA, which caused 1 death and 5 injuries. On July 4, 2017, a PE natural gas pipeline in Songyuan City, Jilin Province, China, leaked and exploded during maintenance, resulting in 7 deaths and 85 injuries.

To investigate the process and damage characteristics of gas pipeline leakage explosion, Zhian et al. [19] used fluent to simulate the propagation law of gas explosion flame and pressure wave in the pipeline and verified with experiments. Ye et al. [20] carried out theoretical analysis and experimental study on the influence of wall heat effect on gas explosion during its propagation, and results show that the influence of wall heat loss on gas explosion intensity is significant, which will affect explosion strength, flame propagation velocity, peak overpressure, and the peak flame propagation velocity and, as the adiabatic degree increases, the effects become more important. Cirimello et al. [21] analyzed a pipeline explosion accident in Argentina, mechanical tests and chemical analysis were conducted on the accident pipe, and the witness descriptions at the scene of the accident were compared to determine the actual process of the explosion accident. Wang et al. [22] used CFD numerical simulation to analyze the natural gas explosion accident in Manhattan, New York. The simulation results were consistent with the actual accident damage, and the location of ignition source was further determined. In addition, many studies have been carried out on the inhibitory mechanism of gas explosion $[23,24]$.

In order to accurately assess the influence of leakage explosion accidents on the pipelines and the surrounding environments and reduce the severity of the accidents, Guo et al. [25] studied the impact damage law of leakage explosion on buried adjacent pipes; by comparison and discussion, they proposed that compared to increasing the pipe thickness, the risk of pipeline accidents can be reduced more by increasing the pipe spacing. Wang et al. [26] numerically simulated the overpressure and deformation of the overhead gas pipeline caused by the leakage explosion of the adjacent pipes under different parallel spacing, and the safety risks of different pipelines were assessed. Wen et al. [27] conducted numerical simulation study on the damage of the adjacent pipeline in the parallel natural gas pipeline in the tunnel. The stress and velocity response of the pipeline under different leakage sizes, parallel spacing, and wind speeds were discussed. Du et al. [28] numerically studied the dynamic response of the defective aluminum pipes under inner gas explosion loading, and an experimental verification was carried out. Russo and Parisi [29] proposed a procedure to assess the damage of buildings caused by gas pipeline explosion, and the minimum safety distance between the pipeline and the building can be determined. Considering different leakage quantities and ranges, Wang et al. [30] simulated the gas explosion in buildings through CFD explosion simulation software, the propagation process of shock waves in buildings was analyzed, and the typical explosion wave curves at different locations were plotted, and the numerical simulation results were consistent with the actual damage of the accident. Sklavounos and Rigas [31] proposed a method to estimate the safety distance near oil and gas pipelines and held that the safety distance depends largely on atmospheric conditions and the safety distance is more sensitive to pipeline size than working pressure.

Based on the above literature analysis, it is found that the current research on the leakage explosion of natural gas pipelines is mainly for cast iron pipes and steel pipes, and the research content is mostly the dynamic response between parallel adjacent pipes under leakage explosion loads. It is rare to take the urban pipe network as the background and the commonly used PE natural gas pipeline as the research object to study the damage effect of the leakage explosion accident [32, 33]. Based on the existing problems, ANSYS/LS-DYNA was used in this study to establish the leakage explosion models of buried PE pipelines under pavements. Considering the coupling effect between pipelines and soil, the dynamic response of buried PE pipelines under pavements under blast loading was studied. The damage laws of pipelines and pavements under different buried depths and explosive equivalents were discussed. The research results can provide theoretical basis for municipal pipeline construction design and urban safety planning and offer references for the risk assessment of gas explosion in buried pipeline, which are of great significance for protecting the safety of urban environment and residents.

\section{Simulation Methodology}

2.1. Fundamentals. The explosion process in a natural gas pipe is a flow process of shock waves with high temperature and pressure in restricted space. To simplify the calculation, the following assumptions were made: 
(1) Gravity effect and delivery pressure of pipe are not considered

(2) The pipe is ideal elastic-plastic, regardless of the joint between pipe sections

(3) The soil and pavements are uniformly continuous and isotropic

(4) The pavement surface is a free surface, and the other directions of soil and pavement extend indefinitely

(5) The contact surface between the pipe and the soil is smooth, and the soil is closely connected with the pavement

(6) The initial ambient temperature is the normal temperature, and explosive is the only heat source in the model

(7) The intermediate process of chemical reactions in the gas explosion is not considered

(8) The release center of the explosive energy is at the origin of the coordinates

The destructive effects of a natural gas explosion on the environments are caused by energy exchange. Based on the above assumptions, the basic governing equations (mass, momentum, and energy equation) can be expressed as

$$
\begin{aligned}
M & =\int_{\Delta_{\varepsilon}} \rho_{\varepsilon} \mathrm{d} v_{\varepsilon}=\int_{\Delta_{x}} \rho_{x} \mathrm{~d} v_{x}=\int_{\Delta_{X}} \rho_{X} \mathrm{~d} v_{X}, \\
\left.\frac{\partial}{\partial t}\right|_{X} \int_{\Delta_{\varepsilon}} \rho_{\varepsilon} v_{\varepsilon} \mathrm{d} v_{\varepsilon} & =\int_{\partial \Delta_{\varepsilon}} t_{i} \mathrm{~d} s_{\varepsilon}+\int_{\Delta_{\varepsilon}} \rho_{\varepsilon} f_{i} \mathrm{~d} v_{\varepsilon} \\
E & =V_{s_{i j}} \varepsilon_{i j}-(p+q) \dot{V}
\end{aligned}
$$

where $\varepsilon$ is the position vector indicating the position of each point in the reference coordinate system; $v$ is the motion velocity of $\varepsilon$ in space; $\partial \Delta_{X}, \partial \Delta_{x}$, and $\partial \Delta_{\varepsilon}$ are the boundaries of the matter domain, the space domain, and the reference domain of any continuum, respectively; $\rho_{X}, \rho_{x}$, and $\rho_{\varepsilon}$ are, respectively, expressed as the density of each substance in the continuum; $t_{i}$ is the force on the unit surface acting on the boundary $\partial \Delta_{\varepsilon}$ of reference region $\Delta_{\varepsilon} ; f_{i}$ is the volume force per unit mass applied to an object; $V$ is the relative volume of the current configuration; $\dot{V}$ is the relative volume deformation speed of current configuration; $s_{i j}$ and $p$ are the deviatoric stress tensor and hydrostatic pressure, respectively; $\varepsilon_{i j}$ is the strain rate tensor; and $q$ is the volume viscous resistance.

Generally, the composition of $\mathrm{CH}_{4}$ in civil natural gas accounts for more than $90 \%$, and thus the composition equation of the explosion reaction can be approximately expressed as follows:

$$
\mathrm{CH}_{4}+2 \mathrm{O}_{2}=2 \mathrm{H}_{2} \mathrm{O}+\mathrm{CO}_{2}+882.6 \mathrm{KJ} / \mathrm{mol}
$$

\subsection{Equivalent of Gas Leakage}

2.2.1. Model of Gas Leakage. There are two types of gas pipe leakage: orifice leakage and fracture leakage, and the possibility of orifice leakage is greater than that of fracture leakage [8]. We assume that the leak orifice is a circular hole with a radius of $0.02 \mathrm{~m}$ to evaluate the gas leakage, and the leakage process is an adiabatic process for the ideal gas to flow out of the pipe. Combining with the Bernoulli equation and the adiabatic equation, the velocity of gas leakage $v$ can be obtained as

$$
v=\varphi \sqrt{\frac{2 k}{k-1} R T\left[1-\left(\frac{P_{0}}{P_{1}}\right)^{(k-1 / k)}\right]}
$$

where $\varphi=0.98$ is the orifice velocity coefficient, which represents the resistance loss during the actual leakage process. $k=1.3$ is the adiabatic exponent. $R=8.314 \mathrm{~J} /(\mathrm{mol} \cdot \mathrm{K})$ is the gas constant. $P_{0}=0.101 \mathrm{MPa}$ is the pressure of external environment. $P_{1}=0.4 \mathrm{MPa}$ is the delivery pressure of pipe. $T=296.15 \mathrm{~K}$ is the environment temperature.

The amount of gas leakage $Q$ is

$$
Q=\varphi C_{D} A P_{1} \sqrt{\frac{M}{R T} \frac{2 k}{k-1}\left[\left(\frac{P_{0}}{P_{1}}\right)^{(2 / k)}-\left(\frac{P_{0}}{P_{1}}\right)^{(k+1 / k)}\right]},
$$

where $C_{\mathrm{D}}$ is the discharge coefficient, which is set to 1 when the orifice shape is a round hole. $A$ is the area of the leak orifice. $M$ is the molecular weight of natural gas and is $0.016 \mathrm{~kg} / \mathrm{mol}$.

Guo et al. [25] used MATLAB to establish a gas leakage diffusion model for buried pipes. The calculation results show that after the pipe leaks, a gas cloud with a certain concentration gradient is formed near the leakage hole, and the radius of the gas cloud increases with the increase of the leakage time. After a certain period of time $(80 \mathrm{~s}$ in the study), the gas in the soil reaches saturation and diffuses from the underground to the ground surface, and then the gas cloud spreads gradually. The gas leaked to the ground is mixed with the air and forms a combustible vapor cloud. When the cloud is ignited, the combustion layer can propagate to the underground pipeline and lead to the explosion of the buried gas pipeline.

2.2.2. Calculation for TNT Equivalent. The destructive effect of vapor cloud explosion is usually determined by the energy it releases. Researchers often convert the vapor cloud energy into TNT equivalents to simulate the damage of gas explosion to the surrounding environment [17, 34]. The conversion equation of gas leakage to TNT equivalent is

$$
W_{T N T}=\alpha \frac{W_{c} Q_{c}}{Q_{T N T}} \lambda,
$$


where $W_{T N T}$ is the TNT equivalent converted from vapor cloud; $\alpha$ is the equivalent coefficient of combustible gas, taking the statistical average of $0.04 ; W_{c}$ is the mass of the combustible component in vapor cloud; $Q_{c}$ is the releasing heat produced by combustion per kilogram, which is $54 \mathrm{MJ} /$ $\mathrm{kg}$; $Q_{T N T}$ is the detonation heat of per kilogram TNT, the average value is around $4500 \mathrm{~kJ} / \mathrm{kg}$; and $\lambda$ is the explosive energy release rate of vapor cloud, which is $5 \%$.

In this study, we assume that the leaking vapor cloud explodes when it just spreads to the ground, and the vapor cloud underground is only discussed, where the combustible gas escapes above the ground is not calculated. By comparison with similar studies, we can assume that the natural gas in the soil reaches saturation after $250 \mathrm{~s}$ and an explosion occurs [25]. The total amount of natural gas leakage calculated by using formula (4) was $208.48 \mathrm{~kg}$, and the equivalent of TNT calculated by using formula (5) was $5 \mathrm{~kg}$.

2.3. Numerical Scheme. In this study, a numerical model was firstly established based on the pipe explosion experiment, and the PE pipe material model and modeling method used in this study were verified. Then, with the explosive equivalent of $5 \mathrm{~kg}$, a tube-soil-pavement explosion model was established to simulate the process of leakage explosion of PE gas pipe with a depth of $1.2 \mathrm{~m}$ under pavement. The failure process of pipe, soil, and pavement and the pressure changes at keypoints were analyzed. After that, with the buried depth of $1.2 \mathrm{~m}$, the degree of damage to pipes and pavements and the dynamic response of keypoints were discussed for explosive equivalents of $1 \mathrm{~kg}, 3 \mathrm{~kg}, 5 \mathrm{~kg}, 7 \mathrm{~kg}$, and $10 \mathrm{~kg}$, respectively. Finally, with the explosive equivalent of $1 \mathrm{~kg}$, the deformation and pressure and stress changes of pipes and pavements under different buried depths were discussed. Considering the minimum buried depth of buried natural gas pipes below urban pavements is $0.9 \mathrm{~m}$, the sizes of buried depths were $0.9 \mathrm{~m}, 1.2 \mathrm{~m}, 1.5 \mathrm{~m}, 1.8 \mathrm{~m}$, and $2.1 \mathrm{~m}$.

Figure 1 shows the schematic diagram of the physical model. The model is divided into five parts, namely, pavement, soil, pipe, TNT explosive, and air part. To eliminate the influence of the boundary, the whole size of the model is $2.6 \mathrm{~m} \times 5 \mathrm{~m}$ in the $x$ and $z$ directions, respectively. The thickness of the pavement is $0.25 \mathrm{~m}$. To study the influence of buried depth on the dynamic response of pipes and pavements, the $y$ direction dimensions are $1.9 \mathrm{~m}, 2.2 \mathrm{~m}$, $2.5 \mathrm{~m}, 2.8 \mathrm{~m}$, and $3.1 \mathrm{~m}$, respectively. On account of the symmetry properties of the models, $1 / 2$ of the models are adopted to save calculation costs. The size of PE gas pipes selected in this study is DN315-SDR11PE pipe, which is commonly used in urban pipelines. A circular leak hole with the radius of $0.02 \mathrm{~m}$ is on the upper part of the pipe, and the TNT is in the center of the pipe below the hole.

The models are meshed by solid164 element. For the purpose of reducing errors and improving the computational efficiency, the minimum size of the mesh near the explosion point is set to $1.5 \mathrm{~cm}$, and the mesh size becomes coarser from the explosion point outward. The total grid number of the numerical model in buried depth of $1.2 \mathrm{~m}$ is 1207560 . The Lagrange algorithm is used for pipes, soil, and pavements to facilitate the simulation of deformation and failure behavior, and the Euler algorithm is used for TNT explosives and air to simulate the propagation of explosive wave. In order to realize the coupling effect of explosive, air, pipeline, and soil during the explosion, the model is established by using the ALE method to make the fluid mesh coincide with the solid mesh, and CONSTRAINED_LAGRANGE_IN_SOLID keyword is used to realize the fluid-structure interaction [26]. CONTACT_AUTOMATIC_SURFACE_TO_SURFACE keyword is used between pipe and soil.

To simulate the semi-infinite soil, the upper surface of the model is set as a free boundary, the symmetric constraint is set on the $\mathrm{Y}-\mathrm{Z}$ plane, and the other four surfaces are set as nonreflecting boundaries.

For the investigation of pipeline leakage explosion accidents, the deformation of pipes and pavements is the focus of attention. In order to facilitate the analysis of the dynamic response of pipes and pavements, reference keypoints are taken at typical locations of the model. As shown in Figure 2, $A, B$, and C keypoints are located on the pipe, and E, F, and G are located on the surface of pavement. The $\mathrm{Z}$ coordinates are $0.7 \mathrm{~m}, 1.4 \mathrm{~m}$, and $2.1 \mathrm{~m}$, respectively. Point $\mathrm{D}$ is on the pavement surface just above the explosive.

2.4. Material Models and Equations of State. The material models and equations of state utilized for the numerical models are concisely explained in the following.

The material model of TNT can be described as HIGH_EXPLOSIVE_BURN material and Jones-Wilkins-Lee (JWL) equation of state. The JWL equation of state describes the explosive pressure as

$$
p=A\left(1-\frac{\omega}{R_{1}}\right) e^{-R_{1} V_{1}}+B\left(1-\frac{\omega}{R_{2} V}\right) e^{-R_{2} V_{1}}+\frac{\omega E_{1}}{V_{1}},
$$

where $p$ is the explosive pressure; $E_{1}$ is the initial explosive energy per unit volume; $V_{1}$ is the initial relative volume; and $A, B, R_{1}, R_{2}$, and $\omega$ are the constant values determined from dynamic experiments. The parameters of TNT are listed in Table 1.

The material model of air medium is described with NULL and LINEAR_POLYNOMIAL equation of state. Null material can be calculated without considering the deviatoric stress and customize the bulk viscosity, which is suitable for defining fluid media such as air. LINEAR_POLYNOMIAL equation of state describes the initial pressure as

$$
\begin{aligned}
& P=C_{0}+C_{1} \mu+C_{2} \mu^{2}+C_{3} \mu^{3}+\left(C_{4}+C_{5} \mu+C_{6} \mu^{2}\right) E_{2}, \\
& \mu=\frac{1}{V_{2}}-1
\end{aligned}
$$

where $P$ is the initial pressure, $C_{0} \sim C_{3}$ are the constants of equation, $E_{2}$ is the initial internal energy per unit reference volume, and $V_{2}$ is the initial reference volume. The specific values of air are listed in Table 2.

The material model of PE pipe is described with PLASTIC_KINEMATIC. Strain rate effect and yield failure are considered, and it is always used for dynamic response 


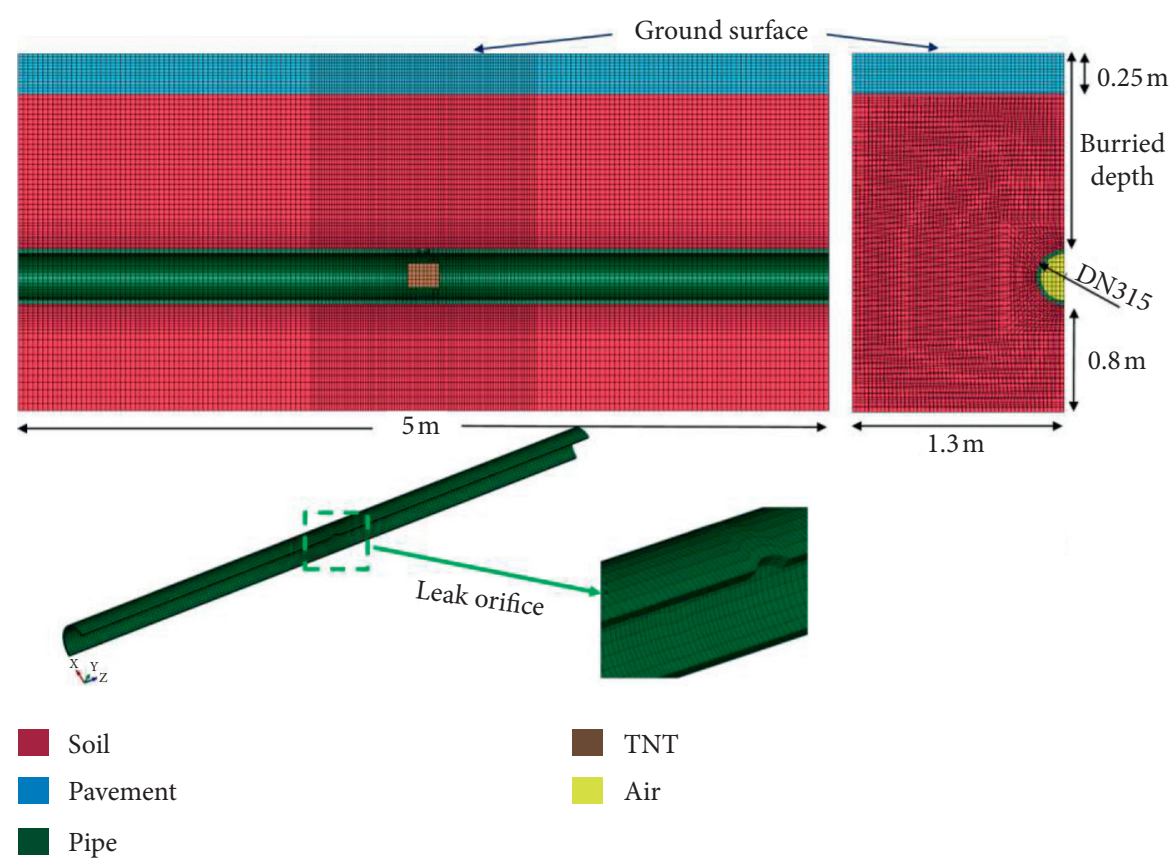

Figure 1: Schematic of the physical model.

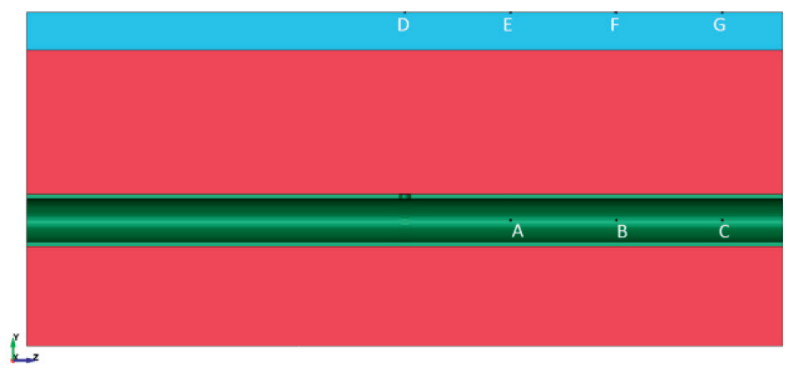

Figure 2: Position of the reference keypoints.

TABle 1: Parameters of TNT.

\begin{tabular}{lcccccccc}
\hline$\rho\left(\mathrm{kg} / \mathrm{m}^{3}\right)(\mathrm{E})$ & $V_{D}(\mathrm{~m} / \mathrm{s})(\mathrm{E})$ & $P_{C J}(\mathrm{~Pa})(\mathrm{E})$ & $A(\mathrm{~Pa})(\mathrm{E})$ & $B(\mathrm{~Pa})(\mathrm{E})$ & $R_{1}$ & $R_{2}$ & $\omega$ & $E_{1}(\mathrm{~Pa})$ \\
\hline 1.4473 & 4.33 & 3.4309 & 2.14411 & 1.8209 & 4.5 & 0.9 & 0.15 & 3.59 \\
\hline
\end{tabular}

TABle 2: Parameters of air.

\begin{tabular}{lcccccc}
\hline$\rho\left(\mathrm{kg} / \mathrm{m}^{3}\right)$ & $C_{0} \sim C_{3}$ & $C_{4}$ & $C_{5}$ & $C_{6}$ & $E_{2}(\mathrm{~Pa})$ & \\
\hline 1.29 & 0 & 0.4 & 0.4 & 0 & 2.55 & 1 \\
\hline
\end{tabular}

analysis of structures under explosive loading. PLASTIC_KINEMATIC describes the yield stress as

$$
\sigma_{y}=\left(1+\left(\frac{\varepsilon}{C}\right)^{1 / p}\right)\left(\sigma_{0}+\beta E_{p} \varepsilon_{p, \text { eff }}\right)
$$

where $\varepsilon$ is the loading strain rate, $C$ and $p$ are the strain rate parameters of Cowper-Symonds, $\sigma_{0}$ is the initial yield stress, $\beta$ is the hardening parameter, $E_{p}$ is the plastic hardening modulus, and $\varepsilon_{p \text {,eff }}$ is the effective plastic strain. The physical parameters of PE pipe are shown in Table 3 [35].
The material models of soil and pavement are described as SOIL_AND_FOAM and SOIL_CONCRETE, respectively $[36,37]$. The specific parameters are listed in Table 4.

\subsection{Model Verification}

2.5.1. Experimental Verification. Zhong et al. [38] conducted an experimental study on the dynamic response of buried PE pipes under explosive loading, and the strain values at typical positions of PE pipes were obtained. In this 
Table 3: Parameters of the PE pipe.

\begin{tabular}{lccc}
\hline$\rho\left(\mathrm{kg} / \mathrm{m}^{3}\right)$ & $E(\mathrm{~Pa})$ & $\mu$ & $E_{\text {tan }}(\mathrm{Pa})(\mathrm{E})$ \\
\hline 959 & 1.079 & 0.4101 & 3.7708 \\
\hline
\end{tabular}

TABle 4: Parameters of soil and concrete pavement.

\begin{tabular}{lcccc}
\hline Material & $\rho\left(\mathrm{kg} / \mathrm{m}^{3}\right)$ & $G(\mathrm{~Pa})(\mathrm{E})$ & $K(\mathrm{~Pa})(\mathrm{E})$ & $P_{C}(\mathrm{~Pa})$ \\
\hline Soil & 1800 & 6.3857 & 310 & -6900 \\
Pavement & 2500 & 1.2510 & 1.66710 & $-2 E 6$ \\
\hline
\end{tabular}

section, a $1: 1$ numerical model of the experiment is established based on the material models and modeling method in Sections 2.1 and 2.2 to verify the reliability of the numerical models in this study. A schematic diagram of the experimental model and numerical model is shown in Figure 3. In the verification model, the TNT magnitude is $200 \mathrm{~g}$, the buried depth of pipe is $1.50 \mathrm{~m}$, and distance from the center of the pipe to TNT is $3.20 \mathrm{~m}$.

Figure 4 shows the stress response of a buried PE pipe under the impact of explosion. The stress response of pipe is mainly concentrated on the end closest to the explosive and transfers from the front surface to the back surface, and at the same time, it spreads far away along the pipe. Due to the small amount of explosive and the long blast center distance, the maximum equivalent stress of the pipe is $1.462 \mathrm{MPa}$; hence, the deformation of pipe is elastic, and the strain value is small. The simulation results are consistent with the experimental results.

Table 5 compares the simulation results of the maximum strain on the surface of the pipe against the experimental values. The comparison results show that the relative errors between the simulation values and experimental values of the measured points are, respectively, $6.87 \%, 10.70 \%$, and $3.23 \%$, and the average relative error is $6.93 \%$. The simulation results are not much different with the experimental results; therefore, the numerical models and methods used in this study are feasible, and the simulation results are reliable.

2.5.2. Grid Independence Analysis and Time Independence Verification. Generally, the grid number and time step have great influences on the accuracy of simulation, and the calculation error gets smaller with the increase of the grid number or the decrease of time step, but too many grid numbers or too small time step may lead to low efficiency of calculation. To solve the problem, grid independence analysis and time independence verification were usually conducted to verify the accuracy of simulation and got an appropriate grid number and time step [39-43]. As shown in Figure 5 and Table 6, In this study, the grid numbers of $806772,1207560,1409480$, and 1893344 were conducted in grid independence analysis, and the time step of $8 e-5 \mathrm{~s}$, $e-4 \mathrm{~s}, 5 e-4 \mathrm{~s}$, and $1 e-3 \mathrm{~s}$ were calculated in time independence verification. In grid independence analysis, the relative error is getting smaller with the increase of grid number, but the fracture width of pipe changes very little when the grid number increases over 1.2 million, indicating that the grid number of 1207560 can achieve the calculation requirement. Based on the grid number of 1207560 , the effect of time step on the calculation result is discussed. As can be seen from Figure 5, the time step changes from $1 e-3 \mathrm{~s}$ to $8 e-5 \mathrm{~s}$, while the calculation result changes little. Under comprehensive consideration, the time step adopted in this study is $1 e-4$.

\section{Results and Discussion}

3.1. Explosion Process of Leakage Gas. The leakage explosions of PE pipe with the explosive equivalent of $5 \mathrm{~kg}$ and a buried depth of $1.2 \mathrm{~m}$ are numerically simulated in this section. Figure 6 shows the propagation process of the shock waves. After the explosion starts from $0 \mathrm{~s}$, the explosion shock waves spread as a sphere to surroundings, and part of them impacts the wall of pipe, but most propagate along the axial direction of the pipe. Within $1 \mathrm{~ms}$, a spherical explosion cavity is formed near the explosion point, indicating that the shock waves have destroyed the pipe wall near the explosion point and directly impact the soil along the fracture. At $1.2 \mathrm{~ms}$ and $2.1 \mathrm{~ms}$, the shock waves reach the end of the pipe and the bottom of pavement, respectively. The shock waves near the explosion point continuously reflect on the free surface of the cavity outside the fracture of pipe, and the high temperature and high pressure continuously do work on the soil. The soil is compressed and deformed, forming a continuously expanding high-pressure explosion cavity that expands outward until it reaches the bottom of the pavement. At $16.8 \mathrm{~ms}$, the bulge phenomenon of pavement can be observed, indicating that the pavement is deformed, and the obvious deformation phenomenon of pavement does not appear at the arrival of shock waves; the bulge phenomenon is caused by the combination of the high temperature and pressure and the soil expansion.

As shown in Figure 7, the PE pipe is deformed under the impact of the explosion, and the effective stress on the pipe decreases with time. The pipe near the explosion point is the first one subjected to the shock waves, resulting in high stress on the pipe, with the occurrence of slight crack around the leak orifice at $0.099 \mathrm{~ms}$. Then the pipe expands and stretches under the effect of the follow-up reflection waves and high temperature and pressure. The energy of shock waves is absorbed by the pipe during the incident and reflection process, leading the pipe to deform. The crack enlarges gradually and forms a fracture finally. With the continuous reflection of shock waves at the interface between pipe and soil, the fracture width continuously increases. By $1.2 \mathrm{~ms}$, the fracture of pipe is no longer increasing. It is noted that during the $1.2 \mathrm{~ms}$ to $4.0 \mathrm{~ms}$ phase, the pipe near the fracture appears a curl inward phenomenon, indicating that the soil explosion cavity width is larger than the pipe fracture width, and the sparse waves reflected in the cavity lead to the continuous deformation of the pipe.

The changes of pressure at reference keypoints on the pipe are shown in Figure 8 . With the increase in distances from the initiation point to reference keypoints, the arrival times of shock waves are delayed, and the maximum pressure on the pipe are decreased. The maximum pressure 


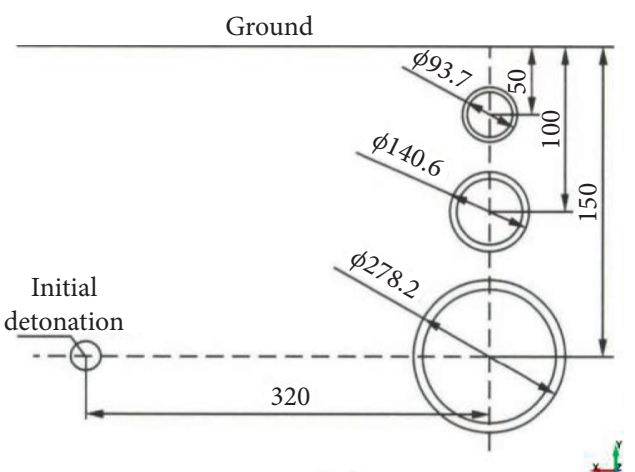

(a)

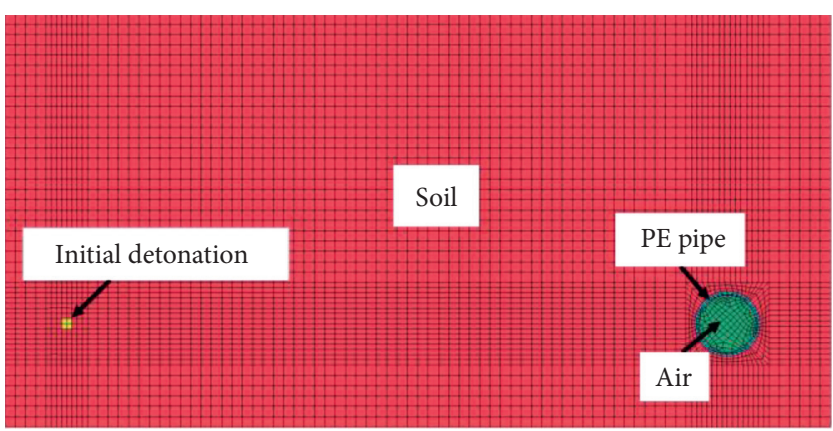

(b)

Figure 3: Schematic diagram of the verification model.

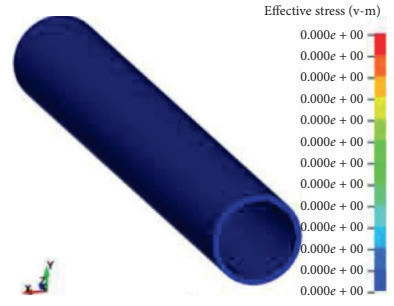

(a)

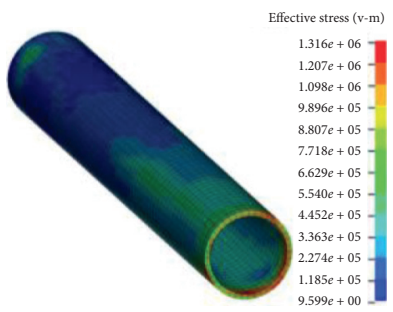

(e)

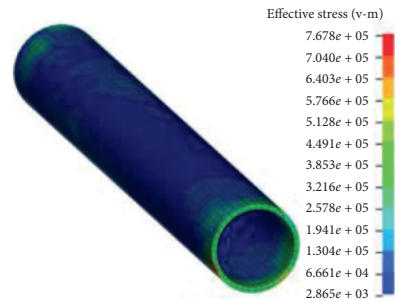

(b)

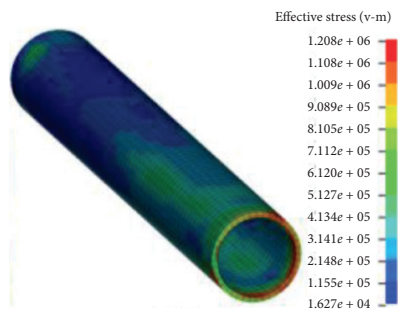

(f)

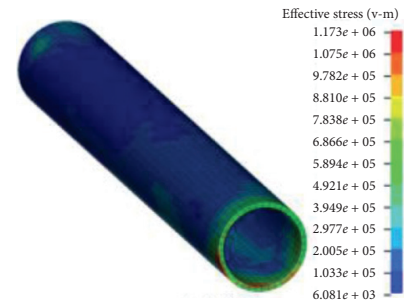

(c)

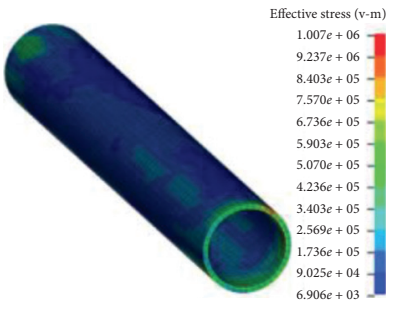

(g)

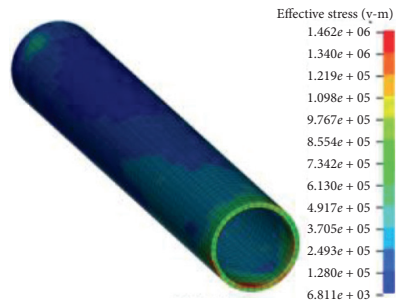

(d)

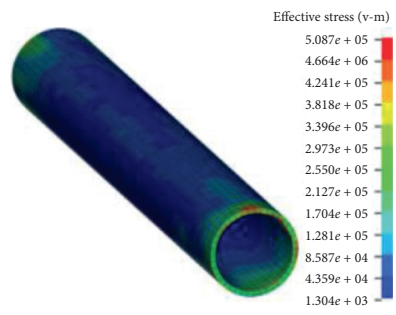

(h)

Figure 4: Stress distribution of PE pipe in the verification model. (a) 0 ms. (b) $5.599 \mathrm{~ms}$. (c) $7.799 \mathrm{~ms}$. (d) $9.799 \mathrm{~ms}$. (e) $11.799 \mathrm{~ms}$. (f) $12.999 \mathrm{~ms}$. (g) $17.399 \mathrm{~ms}$. (h) $40.0 \mathrm{~ms}$.

TABLE 5: Comparison with experimental results.

\begin{tabular}{lccc}
\hline & Experiment & Simulation & Relative errors (\%) \\
\hline Cyclic tensile strain $(\mu \varepsilon)$ & 252.44 & 235.10 & 6.87 \\
Cyclic compressive strain $(\mu \varepsilon)$ & 436.18 & 482.85 & 10.70 \\
Axially strain $(\mu \varepsilon)$ & 328.01 & 338.61 & 3.23 \\
\hline
\end{tabular}

at point $\mathrm{A}$ is $11.4 \mathrm{MPa}$, while the maximum pressure at point $\mathrm{C}$ decreased to $7.64 \mathrm{MPa}$. Under the effect of the follow-up reflected wave and the coupling of pipe and soil, the pressure on the pipe continuously fluctuates and tends to zero.

Figure 9 shows the displacement vector diagram and strain state of the pavement in different views. The maximum bulge height of the pavement is $8.99 \mathrm{~cm}$, and the maximum effective plastic strain is $3.07 \mathrm{E}-5$. Under the explosive loading, the effective plastic strain is produced on the pavement, and the high strain mainly appears in the area directly above the explosion point. Since most of the energy of the upward propagating shock waves is absorbed and converted when it passes through the pipe and soil media, the deformation of the pavement is small, with a slight bulge phenomenon. From the top view, the pavement just above the explosion point is most severely deformed and shapes a circle bulge. The deformation gradient of pavement is most sparse along the axial of pipe, and the entire deformation region distributes as an ellipse.

Figure 10 shows the energy variation and dynamic response of the pavement under explosive loading. The total energy is the sum of internal energy and kinetic energy; the 


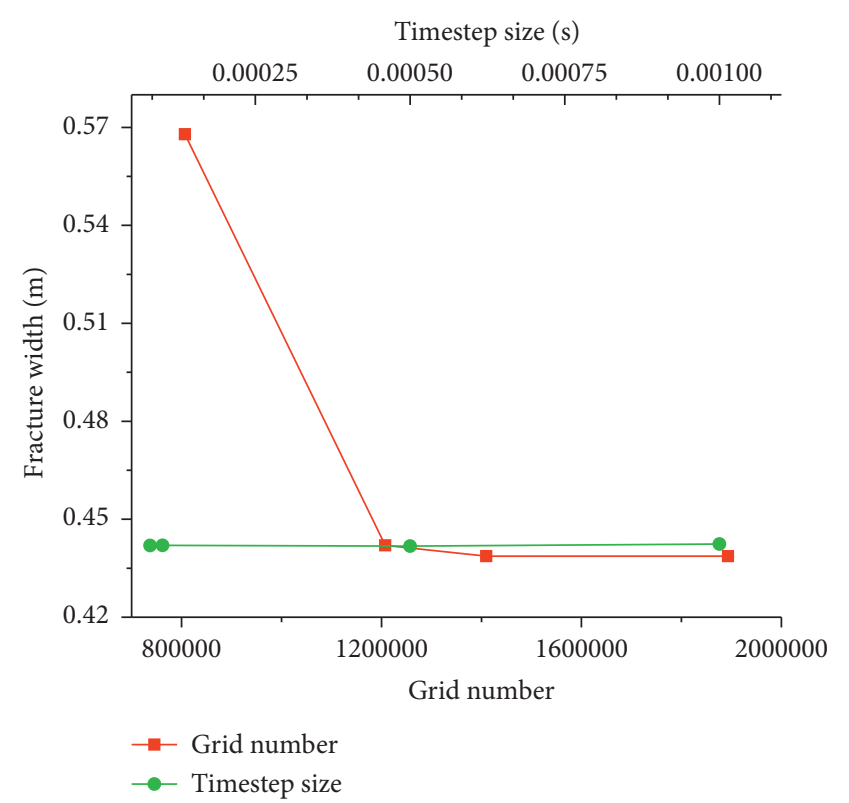

FIGURE 5: Grid independence and time independence verification diagram.

TABLE 6: Variation of fracture width with grid number and time step.

\begin{tabular}{lcccc}
\hline Grid number & 806772 & 1207560 & 1409480 & 1893344 \\
\hline Fracture width (m) & 0.56789 & 0.44201 & 0.43871 & 0.43868 \\
Relative error (\%) & 28.5 & & -0.74 & -0.75 \\
\hline Time step (s) & $8 e-5$ & $1 e-4$ & $5 e-4$ & $1 e-3$ \\
\hline Fracture width (m) & 0.44195 & 0.44201 & 0.44176 & 0.44239 \\
Relative error (\%) & -0.01 & & -0.05 & 0.08 \\
\hline
\end{tabular}

kinetic energy mainly represents the displacement and speed of the pavement, and the internal energy mainly represents the deformation and strain of the pavement. In Figure 10(a), the total energy, kinetic energy, and internal energy of the pavement start to increase at $2.1 \mathrm{~ms}$, which conforms to the arrival time of the shock wave shown in Figure 6. The pavement energy is rising continuously, but the rise speed is decreasing, indicating that the pavement continues to deform under the explosive loading, and the deformation process does not stop until $50 \mathrm{~ms}$. It can be seen from Figure 10(b) that the overpressure of four keypoints raises from $1.8 \mathrm{~ms}, 2.0 \mathrm{~ms}, 2.2 \mathrm{~ms}$, and $2.3 \mathrm{~ms}$, respectively. The overpressure of keypoints in the vicinity of explosion point rises earlier, and the high-overpressure state lasts longer. The closer the keypoint to the explosion point is, the higher the peak overpressure is. The peak overpressure at $\mathrm{D}$ and $\mathrm{E}$ exceeds $0.02 \mathrm{MPa}$, indicating that the pedestrians within the distance of $0.7 \mathrm{~m}$ will suffer varied degrees of injury according to the overpressure injury criterion.

3.2. Effects of Explosive Equivalent. In this section, the dynamic responses of the numerical models with the explosive equivalents of $1 \mathrm{~kg}, 3 \mathrm{~kg}, 5 \mathrm{~kg}, 7 \mathrm{~kg}$, and $10 \mathrm{~kg}$ are compared, and the buried depth is $1.2 \mathrm{~m}$. Figure 11 shows the fracture widths of the pipes under different explosive equivalents.
The fracture width of pipe is greater under the action of a larger explosive equivalent, and the increase of fracture width with explosive equivalent is nonlinear. The amount of explosive equivalent is decisive for the damage degree of pipe. Compared with the explosive equivalent of $1 \mathrm{~kg}$, the fracture width of $3 \mathrm{~kg}$ explosive equivalent increases by $0.211 \mathrm{~m}$ or $129.2 \%$. The relative increases in the fracture width of $5 \mathrm{~kg}, 7 \mathrm{~kg}$, and $10 \mathrm{~kg}$ of explosive equivalent are between $18 \%$ and $20 \%$. In the case of $1 \mathrm{~kg}$ equivalent, the fracture width at the top of the PE pipe is significantly larger than that in the middle. As the explosive equivalent increases, the fracture shape changes, and the difference of fracture width between the top and the middle decreases.

Figure 12 shows the changes of maximum pressure at different locations of the pipe for different explosive equivalents. As the explosive equivalent increases, the maximum pressure at different locations of pipe increases. The maximum pressure at point $\mathrm{A}$ increases rapidly and has a linear relationship with the explosive equivalent, but the maximum pressure at point $B$ and $C$ raises not much. The increasing rate of pressure at point $\mathrm{A}$ under different equivalents changes little and is greater than that at points $\mathrm{B}$ and C. It is shown that the increase of explosive equivalent is directly related to the change of energy in the vicinity of the explosion point, and most of the increased explosive energy involved in the deformation of pipe and soil which transformed into deformation energy and thermal energy, and only a small part of the energy propagates along the axial direction of the pipeline.

Figures 13 and 14 show the energy changes and dynamic responses of the pavement under different explosive equivalents. As shown in Figure 13, the pavement absorbs more energy with the increase of explosive equivalent. When the explosive equivalent is $1 \mathrm{~kg}$, the energy of pavement reaches peak and then slowly decreases and finally stabilizes at a small value, indicating that the explosion has little impact on the pavement. When the explosive equivalent increases to $3 \mathrm{~kg}$ and $5 \mathrm{~kg}$, the energy of pavement reaches peak and then stabilizes at a large value, the pavement is greatly affected by the explosion impact. When the explosive equivalent is $7 \mathrm{~kg}$ and $10 \mathrm{~kg}$, the energy of pavement continues to rise, but the energy is still not stable at $0.05 \mathrm{~s}$, indicating that the pavement deformation process still goes on after $0.05 \mathrm{~s}$. With the explosive equivalent increasing, the energy of the pavement increases significantly, and the deformation process lasts longer; consequently, the threat to pedestrians and vehicles become greater. As shown in Figure 14, with the increase of explosive equivalent, the maximum effective plastic stress and overpressure of pavement change approximately linearly. When the explosive equivalent is greater than $5 \mathrm{~kg}$, the pressure spread to the pavement surface exceeds $0.02 \mathrm{MPa}$, which can cause minor injuries to pedestrians. When the explosive equivalent is greater than $7 \mathrm{~kg}$, the pressure spread to the pavement surface exceeds $0.03 \mathrm{MPa}$, and pedestrians may seriously be injured. The increase of leakage amount of natural gas generates more explosive energy, and the damage induced to pipes, pavements, and the pedestrians can be greater. 


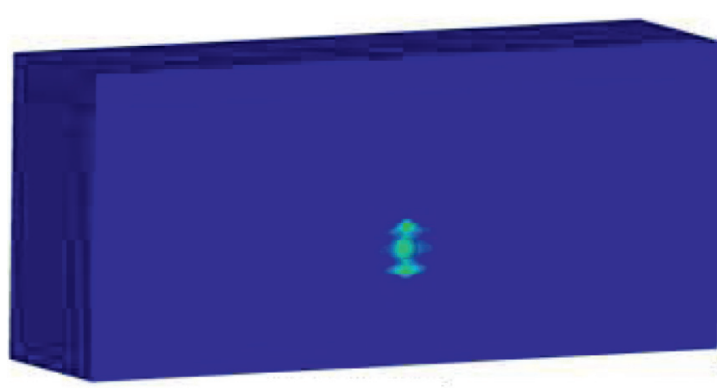

(a)

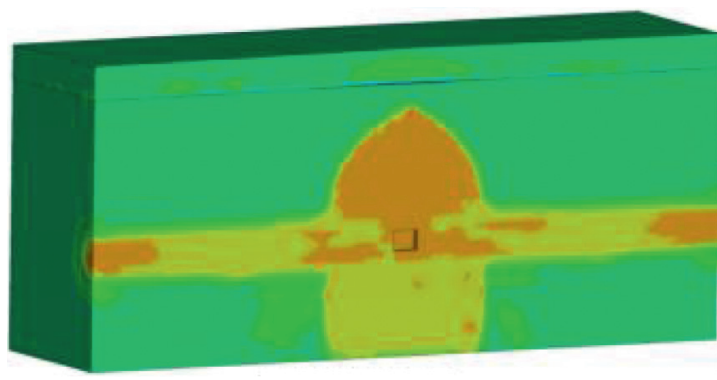

(c)

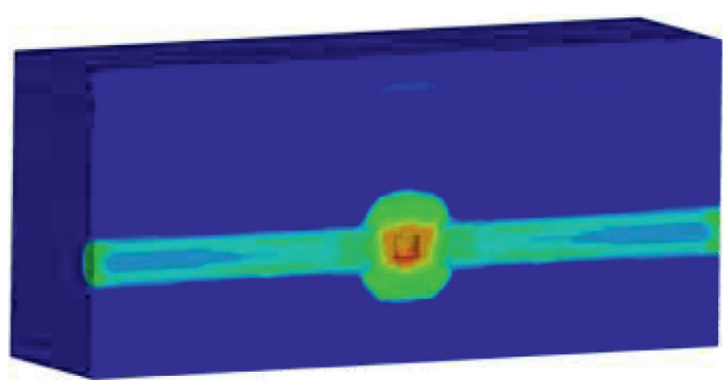

(e)

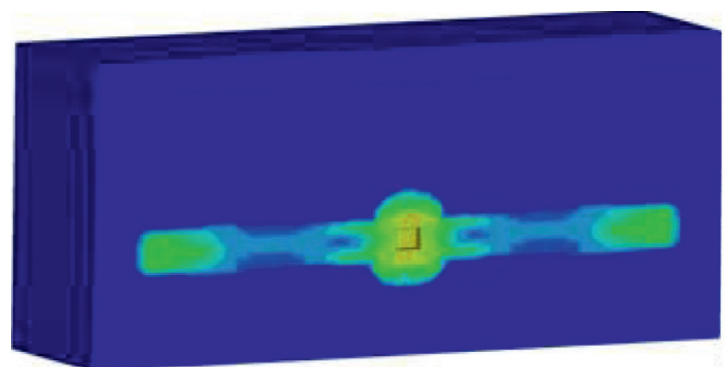

(g)
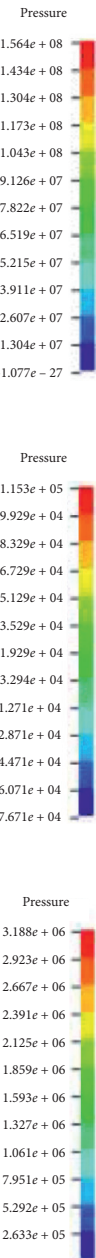

(6)

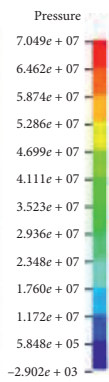

-

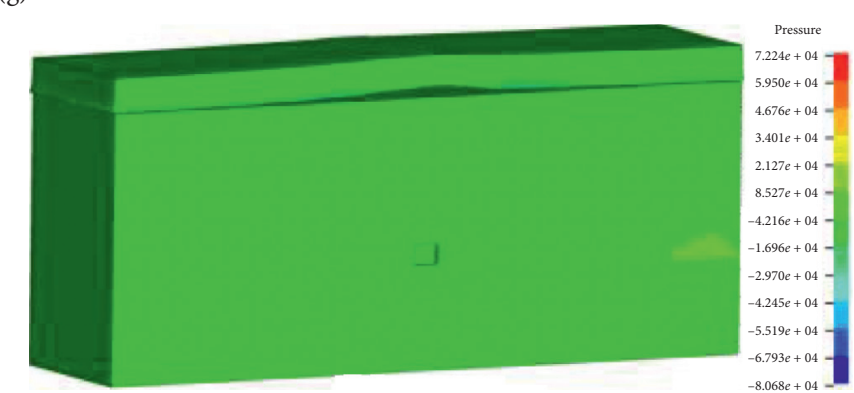

(i)

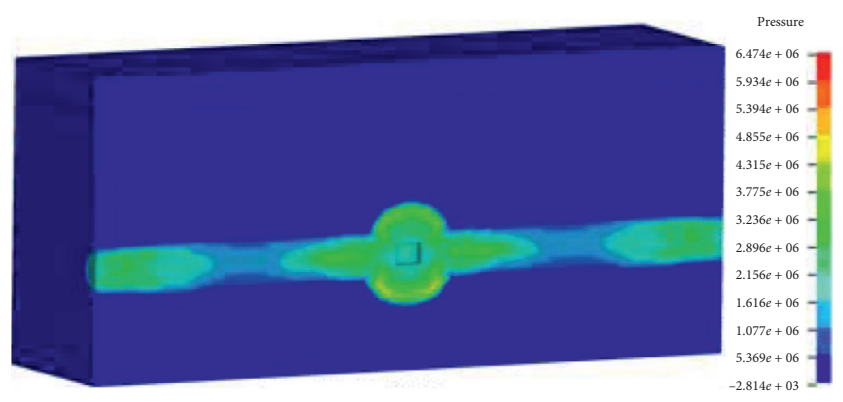

(b)

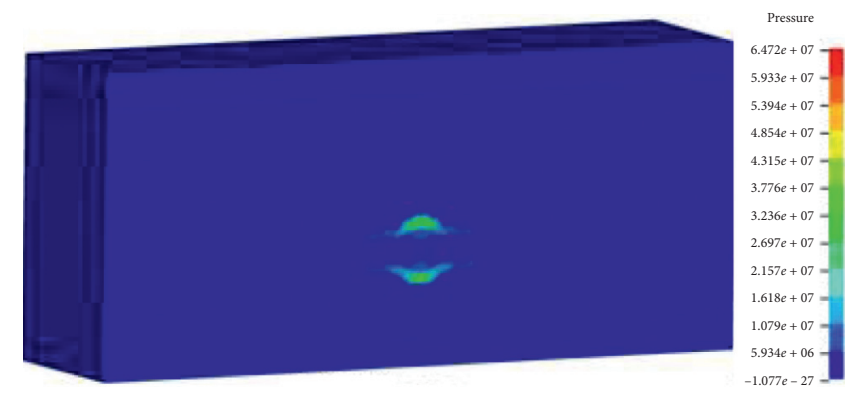

(d)

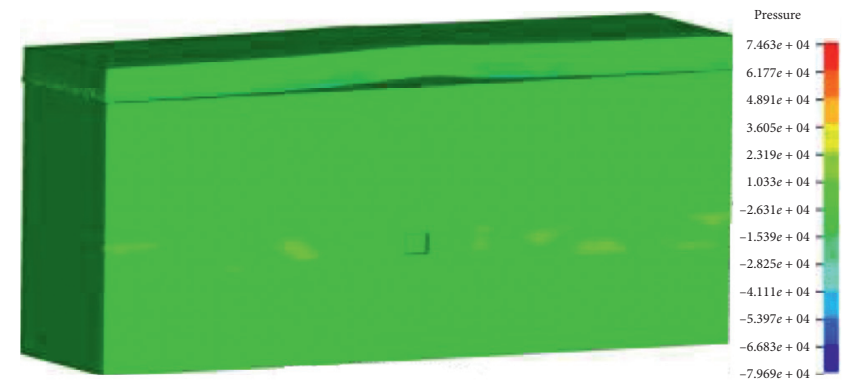

(f)

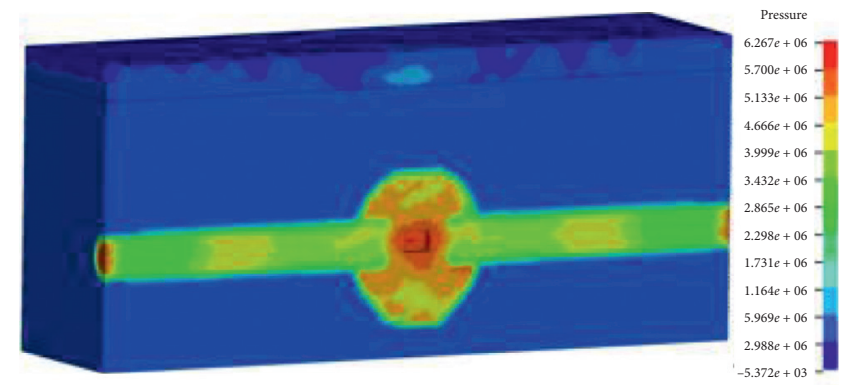

(h)

(g) $0.999 \mathrm{~ms}$. (h) $5.499 \mathrm{~ms}$. (i) $50.0 \mathrm{~ms}$. 


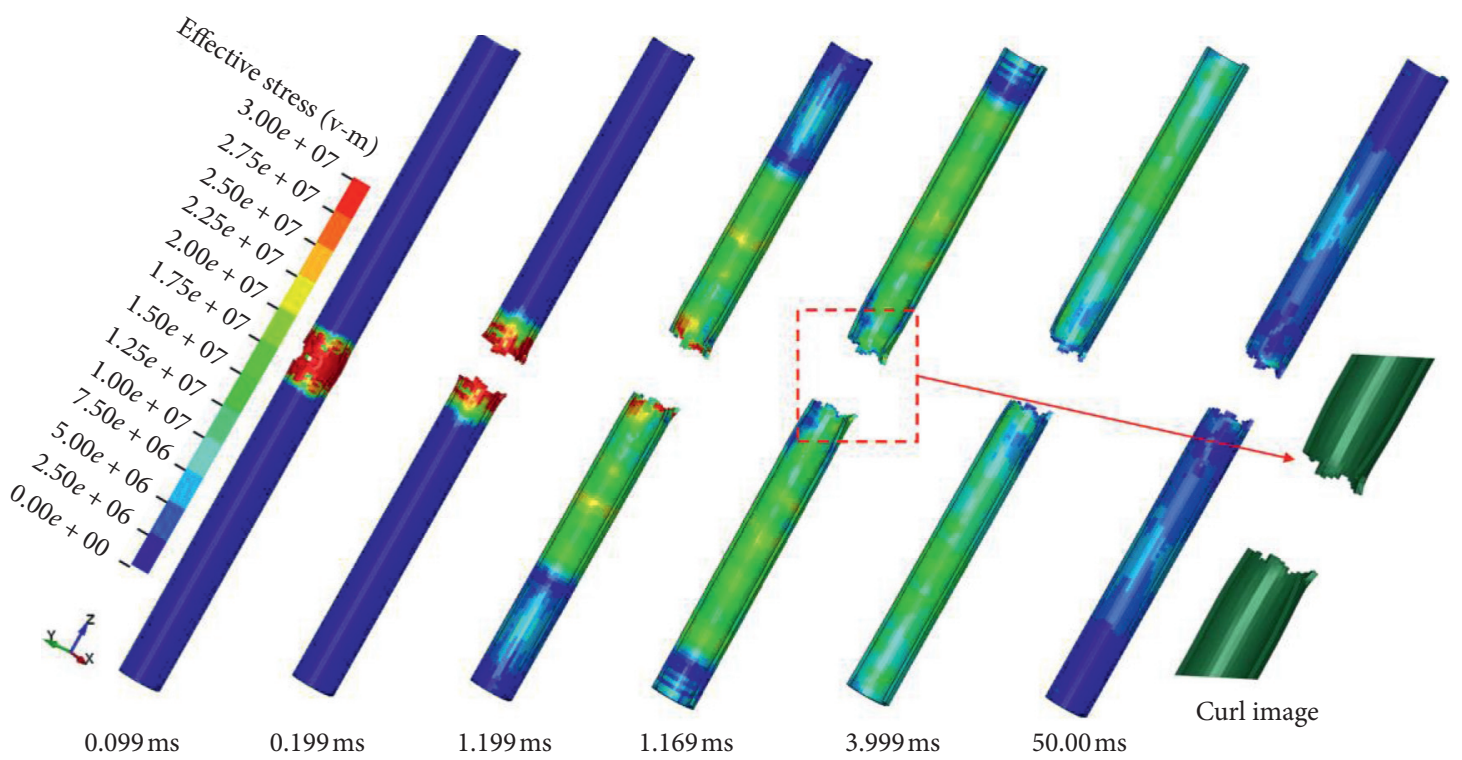

Figure 7: Stress distribution and damage process of the PE pipe.

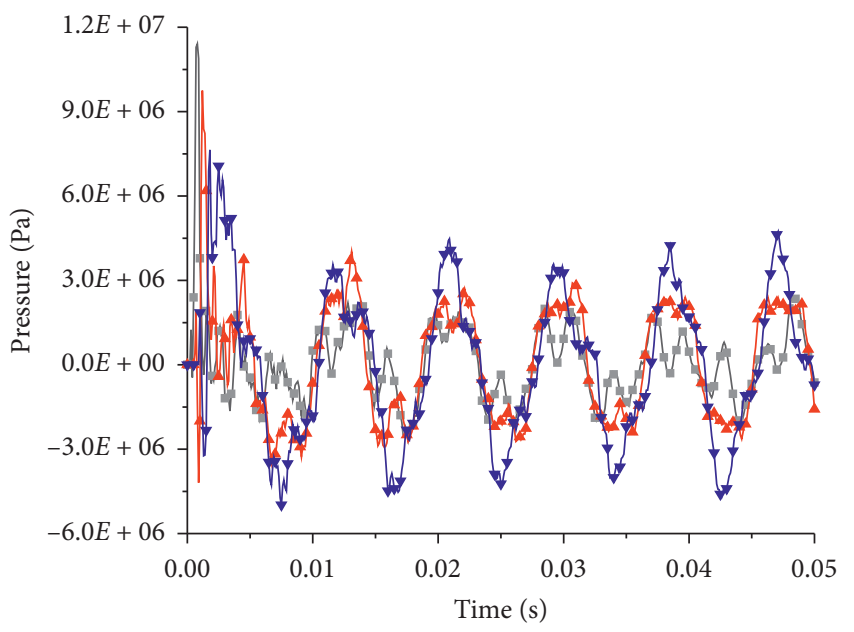

Keypoints

$-\mathrm{A}$

$\triangle \mathrm{B}$

Figure 8: Pressure-time curve of keypoints in different pipes.

Figures 15 and 16 show the deformation and strain response of the pavement under different explosive equivalent conditions. The deformation value of the pavement depends linearly on the explosive equivalent. The strain area of the pavement is concentrated above the explosion point. The deformation value increases with the increase of explosive equivalent, but the increasing rate decreases gradually. When the explosive equivalent is $3 \mathrm{~kg}$, the bulge starts to appear on the pavement, but the bulge degree is slight.
When the explosive equivalent is $5 \mathrm{~kg}$, an obvious bulge can be seen. When the explosive equivalent adds up to $7 \mathrm{~kg}$ and $10 \mathrm{~kg}$, the bulge shape changes from a cone to an arch. It is predictable that the pavement will rupture as the explosive equivalent continues to increase.

3.3. Effects of Buried Depth. This section discusses the dynamic response of the numerical models with different buried depths, and the explosive equivalent is set to $1 \mathrm{~kg}$. 


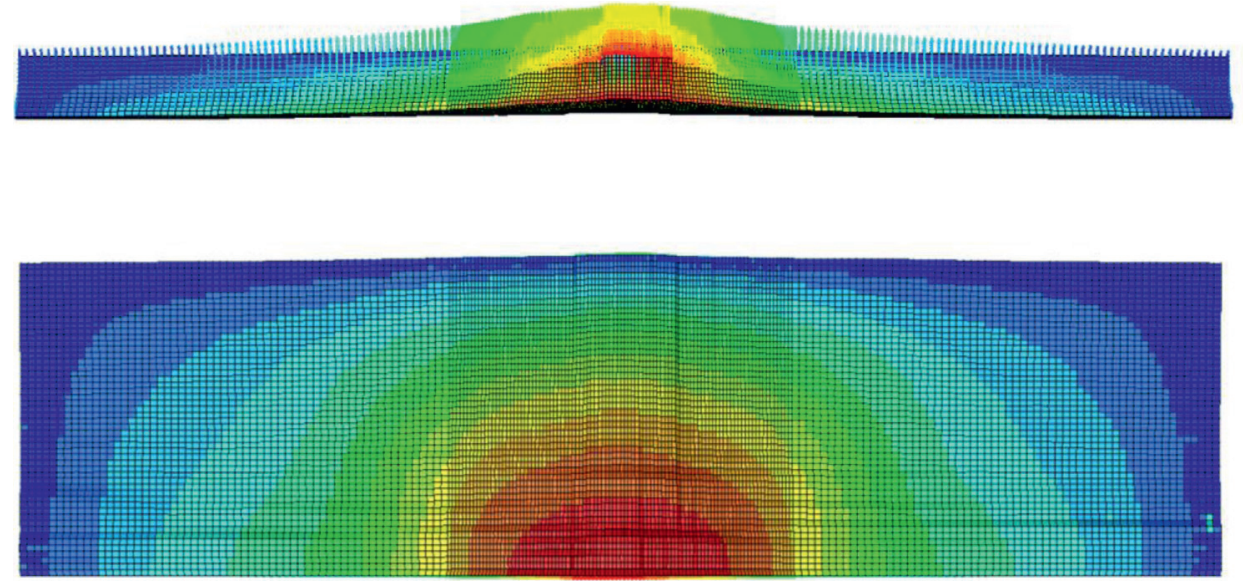

Vectors: Fringe

$8.99 e-02-3.07 e-05$
$8.28 e-02-2.81 e-05$
$7.57 e-02-2.56 e-05$
$6.85 e-02--2.30 e-05$
$6.14 e-02--2.05 e-05$
$5.43 e-02--1.79 e-05$
$4.72 e-02--1.53 e-05$
$4.00 e-02--1.28 e-05$
$3.29 e-02--1.02 e-05$
$2.58 e-02--7.69 e-05$
$1.87 e-02-5.13 e-05$
$1.16 e-02-2.58 e-05$
$4.43 e-03-2.53 e-05$

Figure 9: Deformation and strain distribution of pavements.

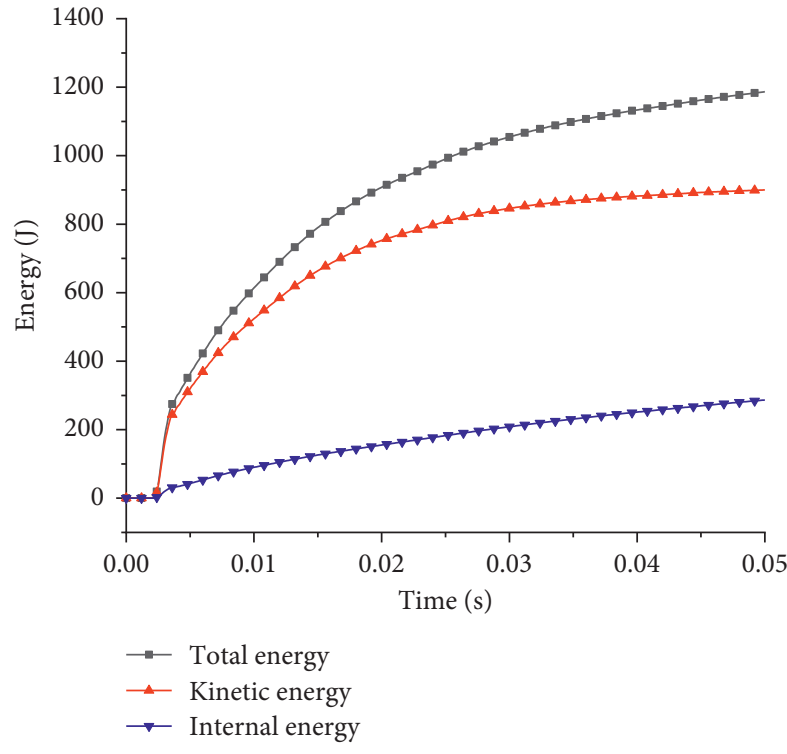

(a)
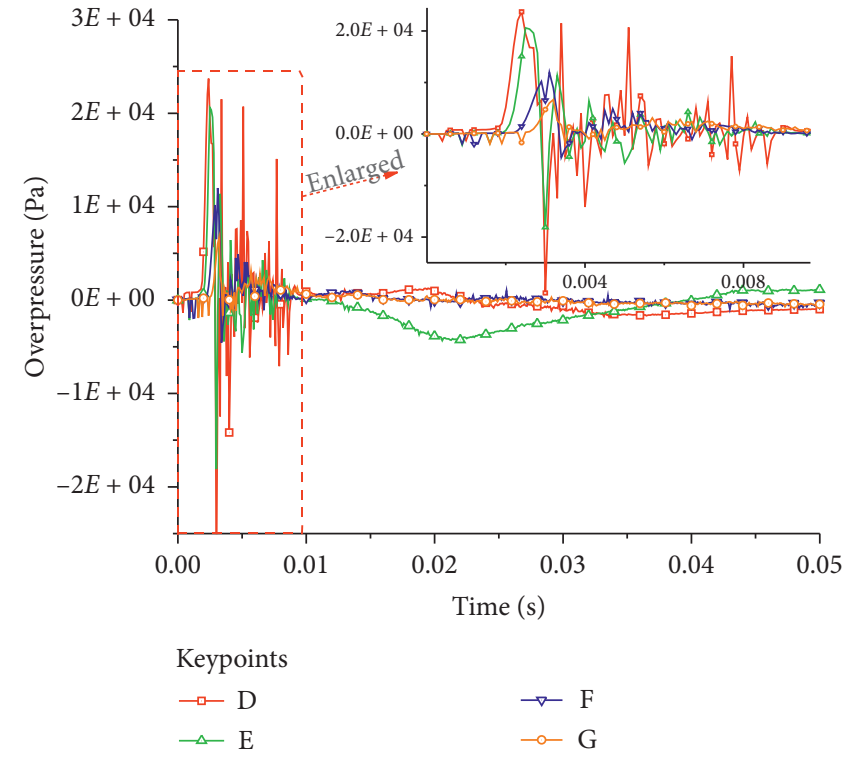

(b)

Figure 10: Dynamic response curves of different pavements.

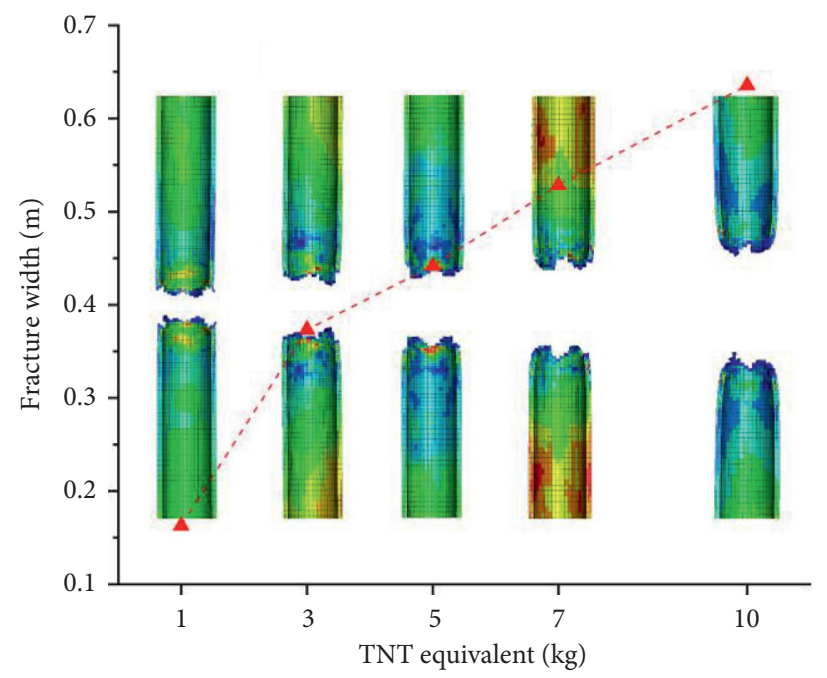

- - Fracture width

Figure 11: Fracture width of pipes under different TNT equivalents. 


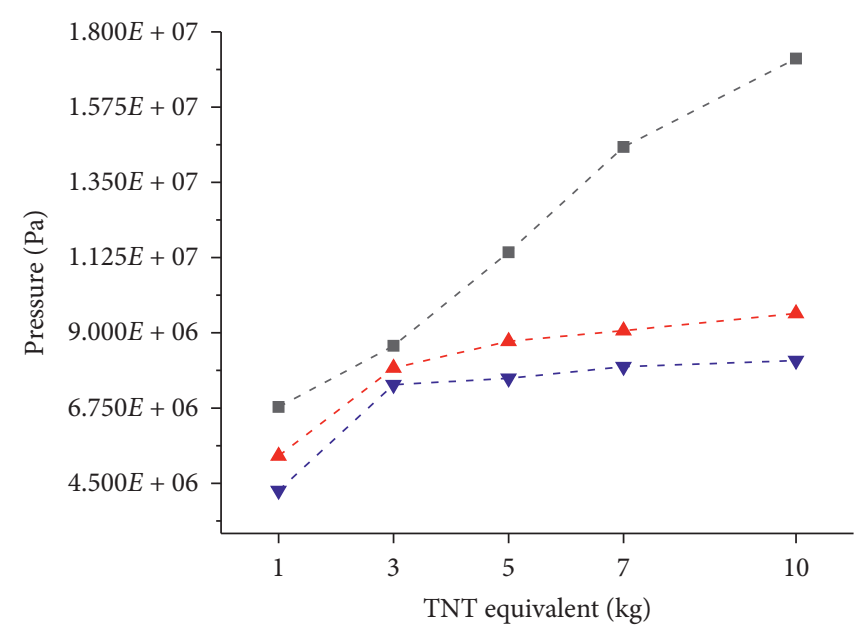

Keypoints

$\begin{array}{ll}-1 & \text { A } \\ -\Delta- & B \\ -\nabla & -\end{array}$

FIgURe 12: Dynamic response of pipes under different TNT equivalents.

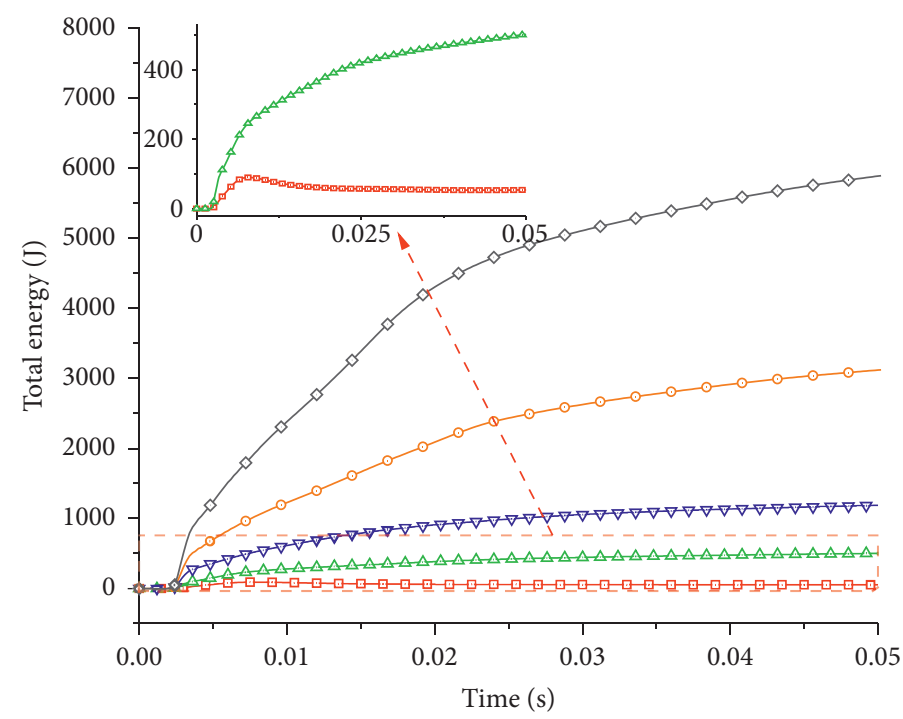

TNT equivalent

$\begin{array}{ll}\rightarrow-1 \mathrm{~kg} & \multimap-10 \mathrm{~kg} \\ \rightarrow-3 \mathrm{~kg} & \multimap-7 \mathrm{~kg} \\ \rightarrow-5 \mathrm{~kg} & \end{array}$

Figure 13: Total energy curves of pavements under different TNT equivalents.

As shown in Figure 17, the variation of the buried depth has little effect on the fracture width of the pipe. The fracture width of the $1.2 \mathrm{~m}$ buried depth is relatively large, but the maximum difference is less than $2.35 \%$.

Figure 18 shows the maximum effective stress and pressure of the keypoints on pipes with different buried depths. The maximum pressure and effective stress of different keypoints on the pipe decrease as the distance from the explosion point increases. The change of buried depth has the greatest influence on the peak pressure at point $\mathrm{C}$, and the pressure difference between the buried depths of $2.1 \mathrm{~m}$ and $1.2 \mathrm{~m}$ at this point is $16 \%$. The effective stress value changes the most at point $\mathrm{A}$, where the difference of effective stress between $2.1 \mathrm{~m}$ and $1.2 \mathrm{~m}$ buried depths is $7 \%$. It shows that the influence of the buried depth on the pressure of the pipeline is larger at the position away from the explosion point, and the influence of buried depth on the pipeline's effective stress is larger near the explosion point. 


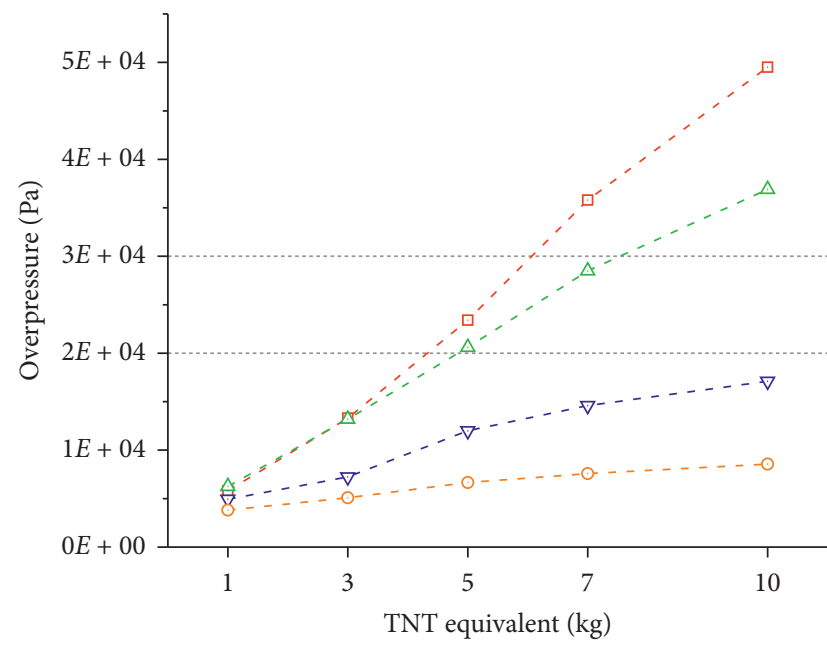

Keypoints

$-\square-\mathrm{D}$

$-\Delta-\mathrm{E}$

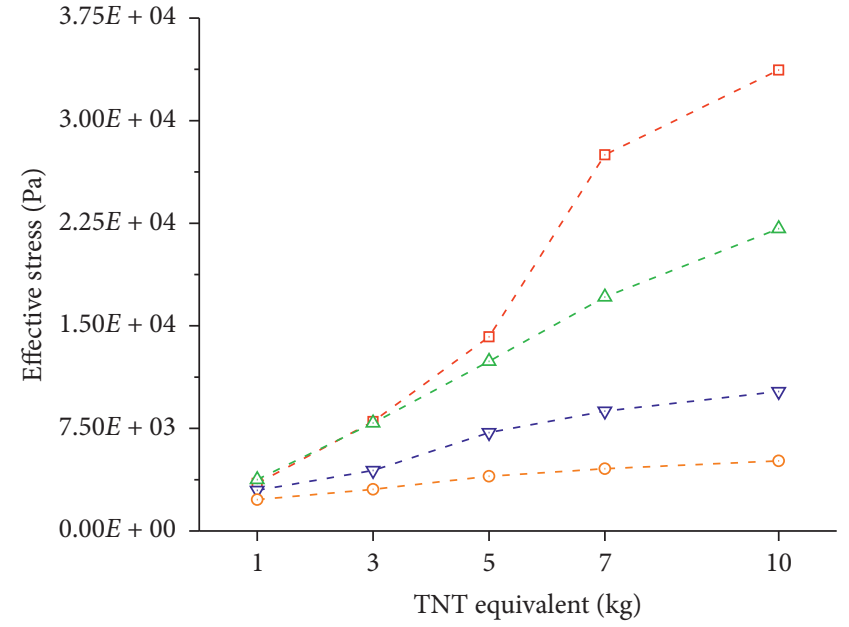

Keypoints

- - D

$-\Delta-\mathrm{E}$
$-\nabla-\mathrm{F}$

$-\odot-G$

(a)

(b)

FIGURE 14: Dynamic response curves of pavements under different TNT equivalents.

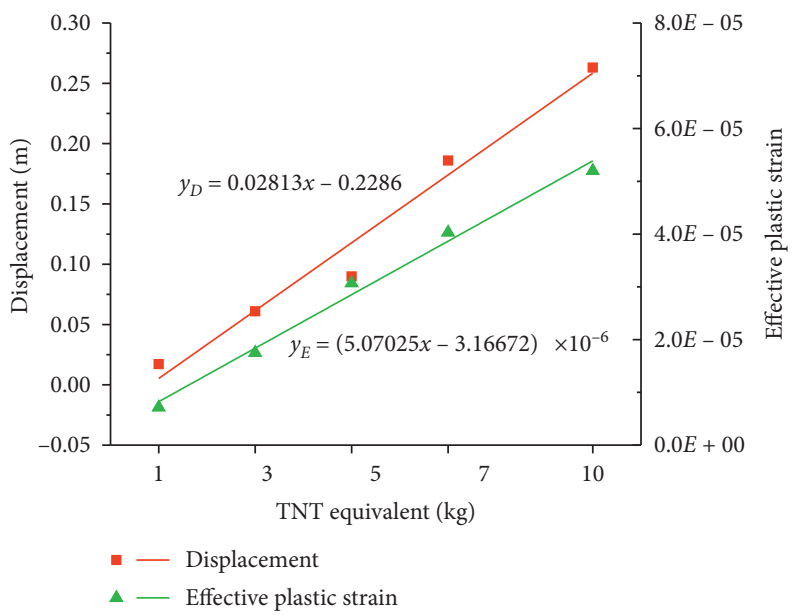

FIGURE 15: Deformation of pavements under different TNT equivalents.

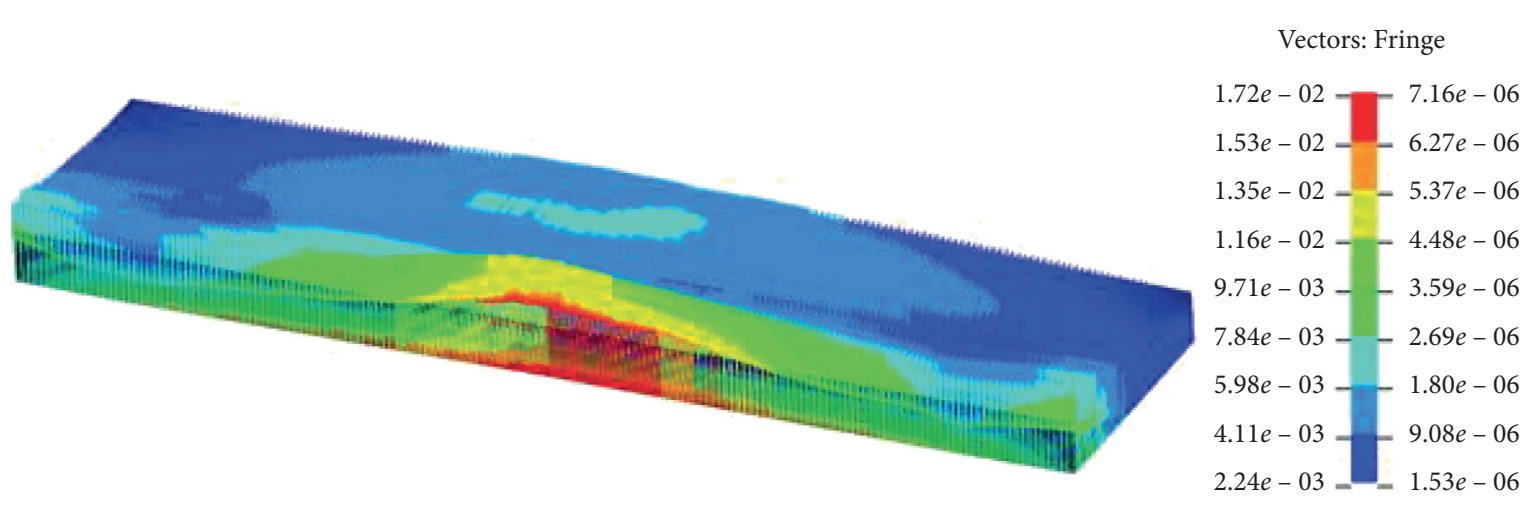

(a)

FIgURE 16: Continued. 
Vectors: Fringe

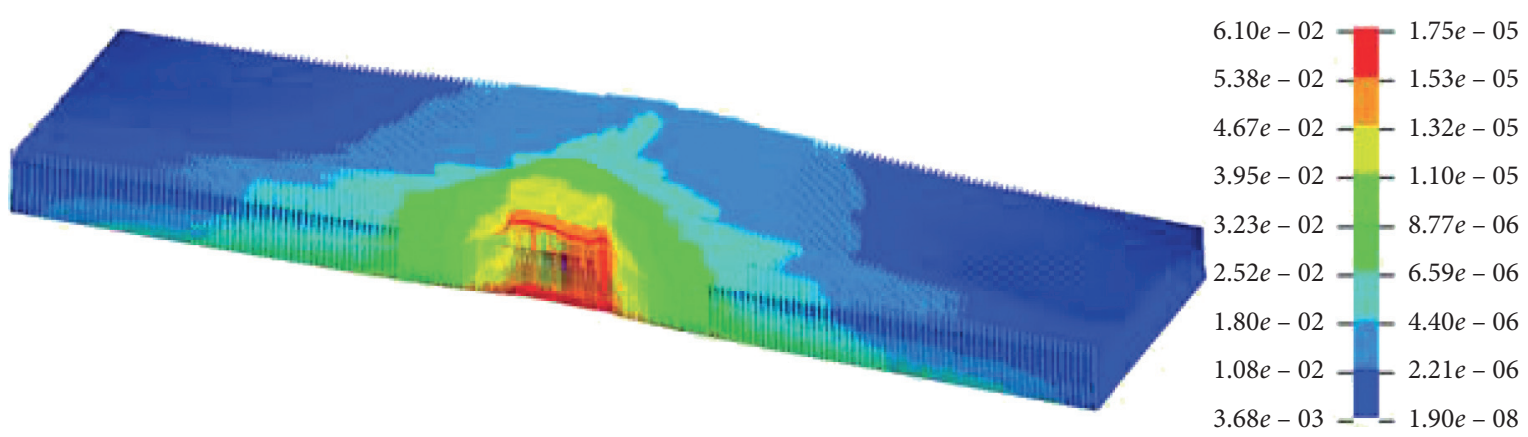

(b)

\section{Vectors: Fringe}

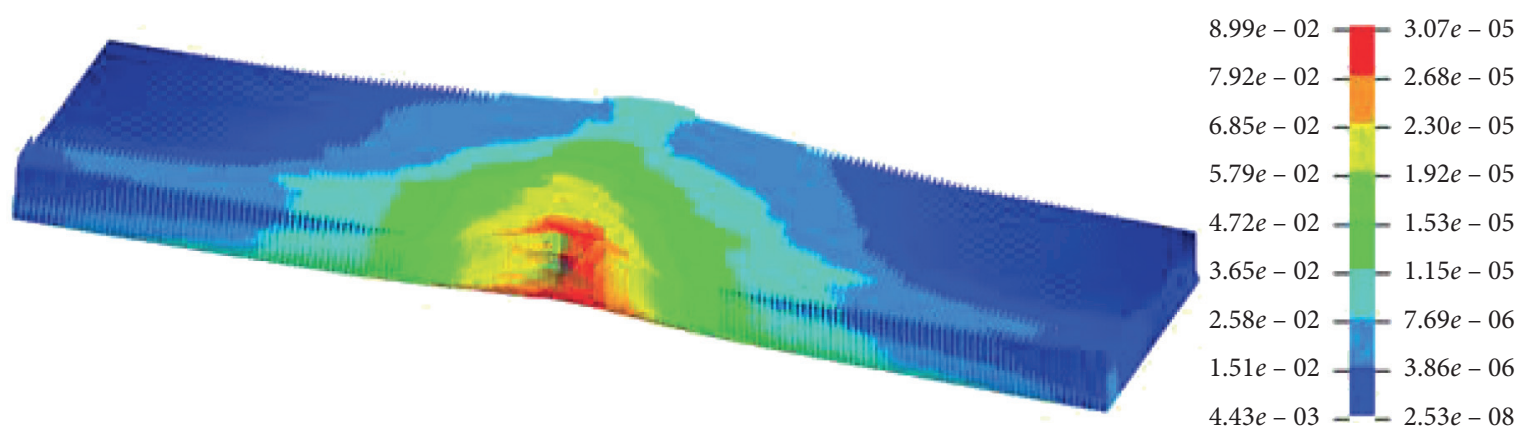

(c)

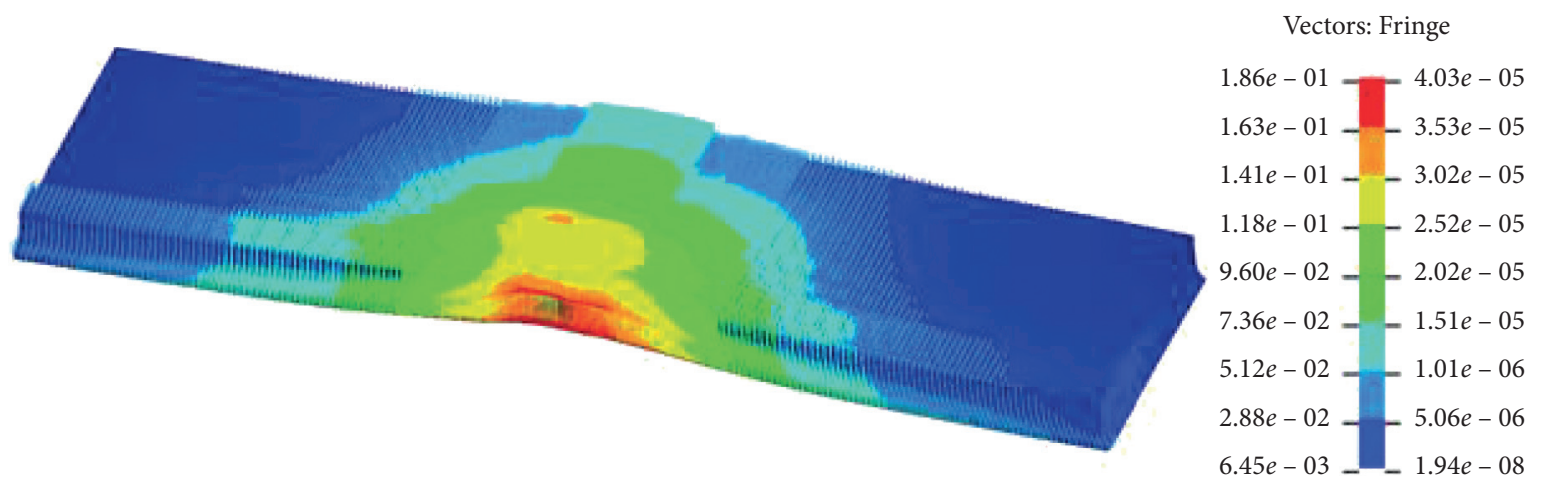

(d)

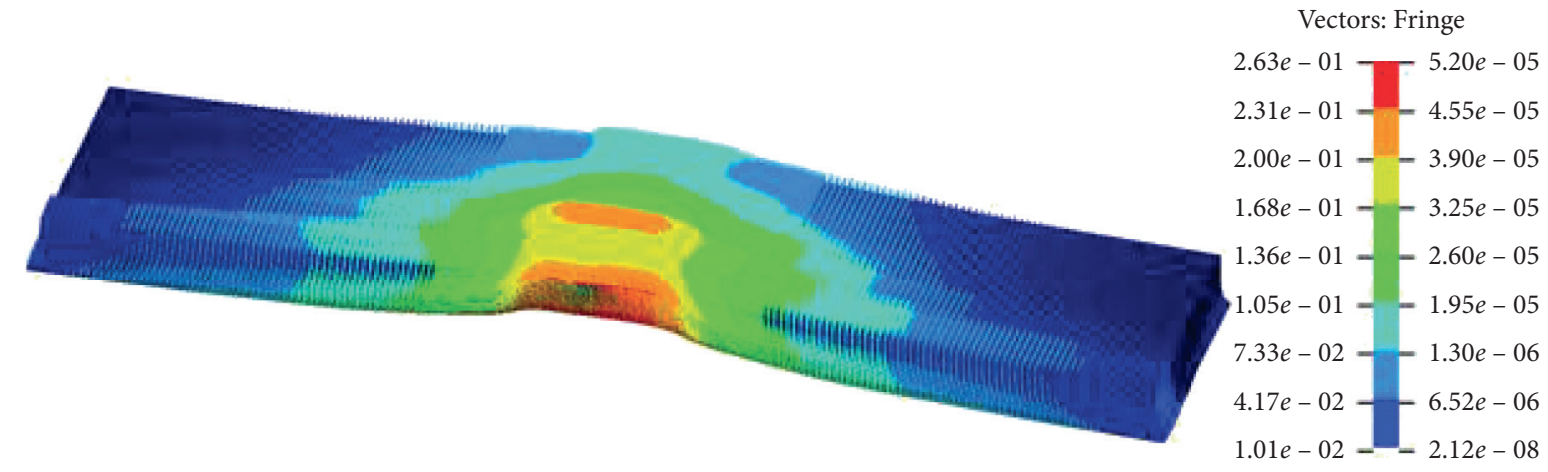

(e)

Figure 16: Displacement and strain distribution of pavements. (a) $1 \mathrm{~kg}$. (b) $3 \mathrm{~kg}$. (c) $5 \mathrm{~kg}$. (d) $7 \mathrm{~kg}$. (e) $10 \mathrm{~kg}$. 


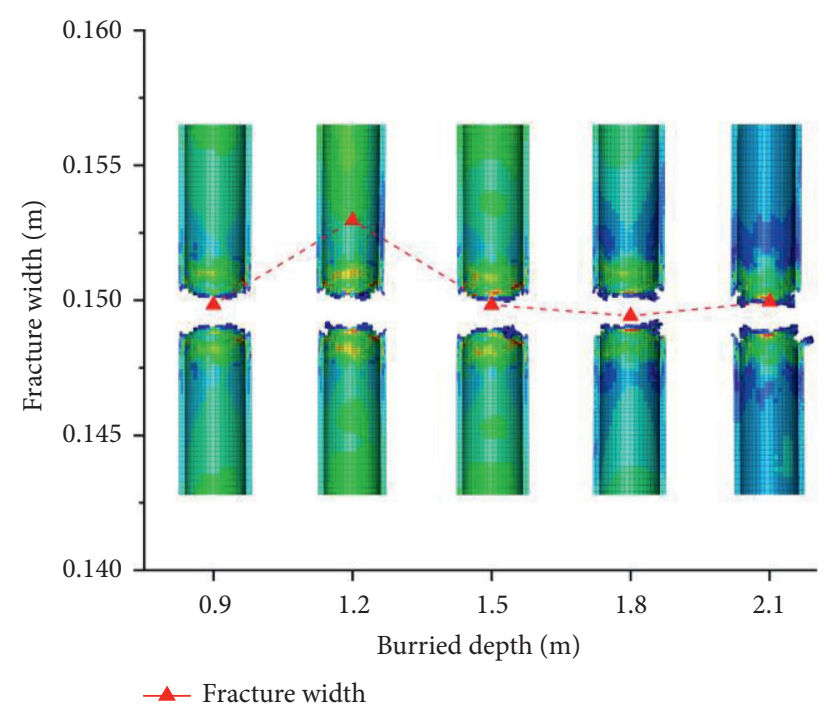

FIgURE 17: Fracture width of pipes under different buried depths.

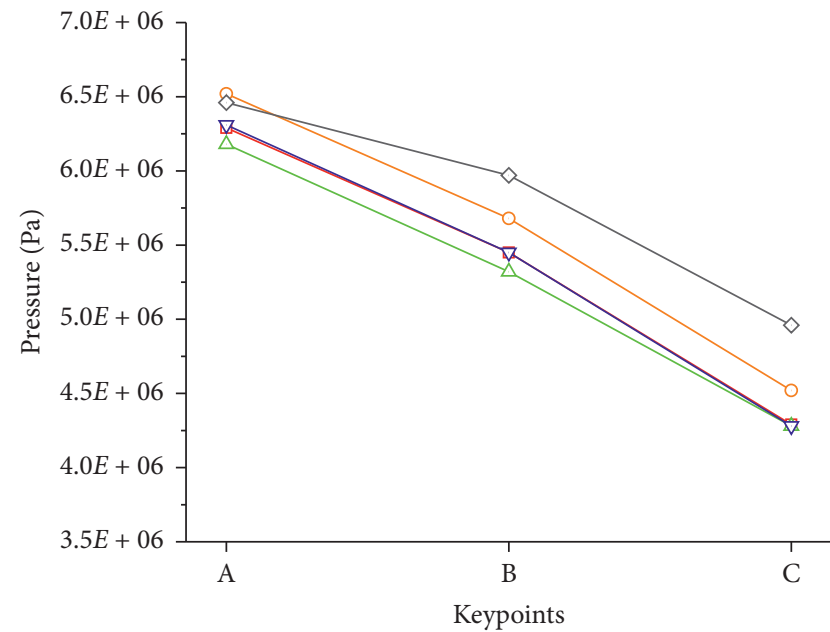

Buried depth(m)

$\begin{array}{ll}\rightarrow-0.9 & -\triangle 1.2 \\ --1.5 & -\circ 1.8 \\ \diamond-2.1 & \end{array}$

(a)

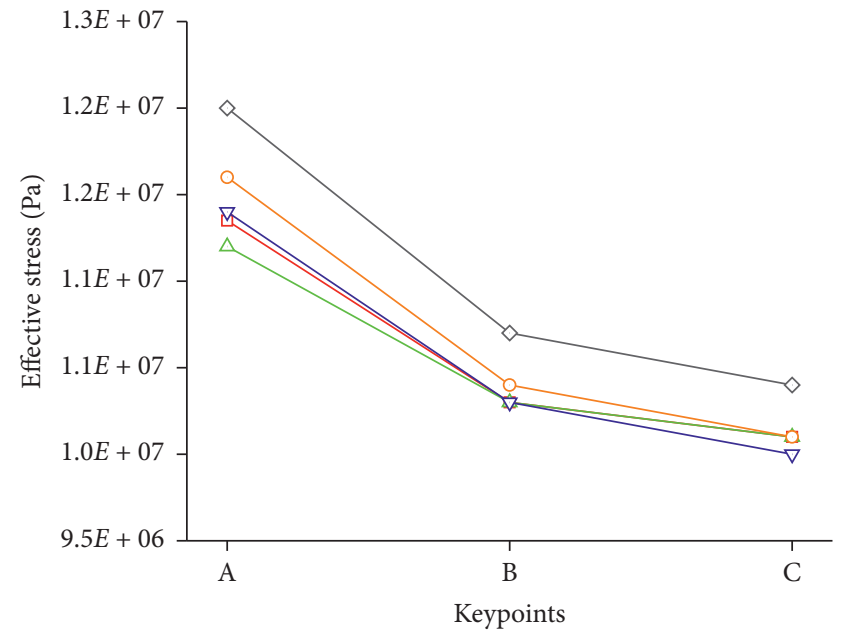

Buried depth(m)

$\begin{array}{ll}\rightarrow-0.9 & -\triangle 1.2 \\ \neg-1.5 & -\circ 1.8 \\ \diamond-2.1 & \end{array}$

(b)

Figure 18: The maximum pressure and effective stress of pipes under different buried depths.

Figure 19 shows the changes of total energy and dynamic response of pavement at different buried depths. As shown in Figure 19(a), with the increase of buried depth, the energy absorbed by the pavement decreases, and the time to reach the peak is delayed. Figure 19(b) shows the relationship between the maximum overpressure and effective stress of keypoint $\mathrm{D}$ and the buried depth. The overpressure of pavements declines with the increase of the buried depth, but the amplitude of decline is decreasing, and the overpressure changes in the form of a concave function. Since the overpressure on the pavement is less than $0.02 \mathrm{MPa}$, pedestrians may be hardly injured.
Figure 20 shows the relationship between buried depth and pavement deformation. As the buried depth increases, the displacement and strain values of the pavement decrease. At $0.9 \mathrm{~m}$ to $1.5 \mathrm{~m}$, the pavement deformation can be effectively reduced by increasing the buried depth. For every $0.3 \mathrm{~m}$ increase in buried depth, the deformation value decreases by about $50 \%$. As the buried depth continues to increase, the pavement deformation continues to decrease, but the reduction is getting lower. The variation law of deformation is similar to that of maximum overpressure and effective plastic strain on pavement. 


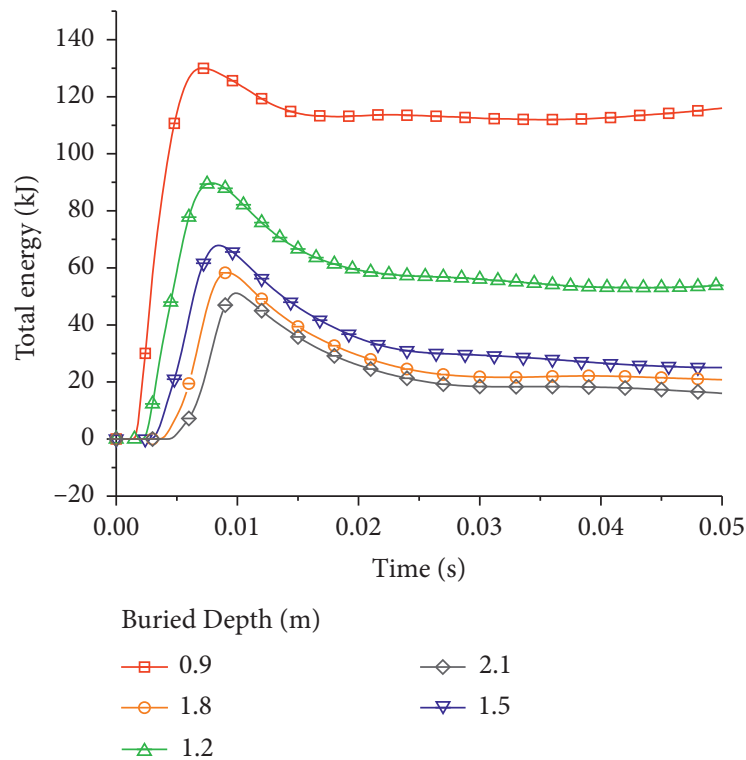

(a)

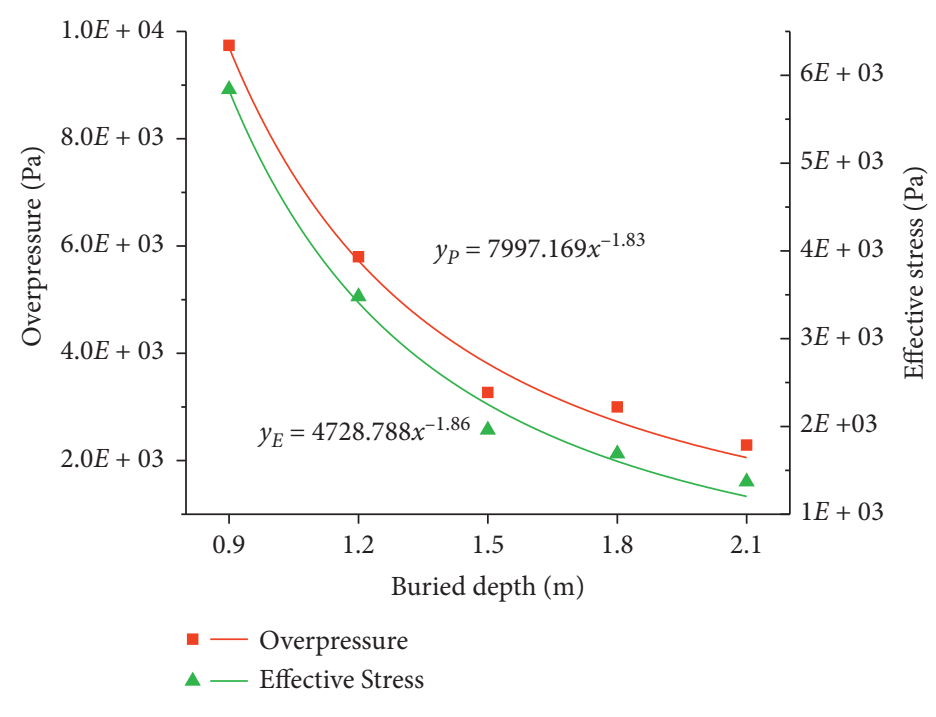

(b)

FIGURE 19: Dynamic response curves of pavements.

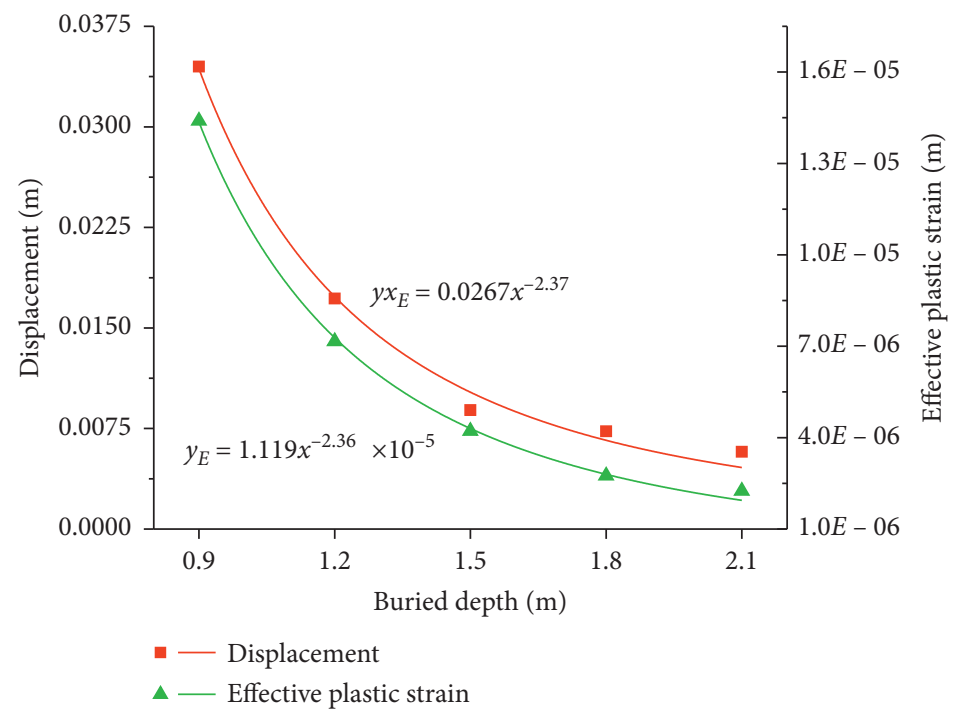

Figure 20: Relationship between buried depth and deformation of pavement.

\section{Conclusions}

In recent years, with the great corrosion resistance and flexibility, the PE pipe has occupied rising proportion in the length of urban natural gas pipeline and has become one of the major natural gas transmission and distribution pipes. However, pipeline leakage explosion accidents continue to occur, accompanied by serious damage to urban environment and casualties. It is a focus of municipal construction design and urban safety planning to improve the safety of urban gas pipeline system. Consequently, it is necessary to study the process and damage effect of leakage explosion in the buried PE gas pipeline. In this study, the gas leakage corresponding to the leakage time is figured up with the formula, and the TNT explosive equivalent is determined. The numerical model of the buried PE pipe under the pavement is established by using ANSYS/LSDYNA. Through simulation analysis, the following conclusions can be drawn:

(1) After the leakage explosion, the PE pipe is fractured, and a spherical explosion cavity is formed in the soil. The pavement above the explosion point bulges upward, and the bulge area is circular in structure.

(2) The size of the explosive equivalent is decisive for the damage degree of pipe and pavement.

The fracture width of the PE pipe increases significantly as the explosive equivalent increases, and the 
fracture shape also changes with the variation of explosive equivalent. As the explosive equivalent increases, the deformation process of the pavement is prolonged, and the deformation degree of the pavement is increased. When the explosive equivalent is greater than $5 \mathrm{~kg}$, that is, when the leakage time exceeds $250 \mathrm{~s}$, the ground overpressure is greater than $0.02 \mathrm{MPa}$, and the pedestrians on the pavement can be injured. As a result, to prevent further accidents, the leaking pipeline should be disposed in time when the leakage signal is detected.

(3) With the increase of buried depth, the damage degree of pipe is little changed. The difference of maximum pressure on the pipe is $16 \%$, and the difference of maximum effective stress is $7 \%$. The deformation degree of the pavement is greatly affected by the buried depth. When the depth is $0.9 \mathrm{~m}$ to $1.5 \mathrm{~m}$, the deformation value decreases by about $50 \%$ for each $0.3 \mathrm{~m}$ depth increase. When the buried depth is greater than $1.5 \mathrm{~m}$, the maximum overpressure of the pavement is less than $0.1 \mathrm{MPa}$. The variation rule of pavement deformation is similar to that of maximum overpressure and effective plastic stress, and they change in the form of concave functions with the increase of buried depth. Therefore, under normal circumstances, the buried depth of urban gas pipeline should be greater than $1.5 \mathrm{~m}$.

\section{Data Availability}

The data used to support the findings of this study are available from the corresponding author upon request.

\section{Conflicts of Interest}

The authors declare they have no conflicts of interest.

\section{Acknowledgments}

The authors gratefully acknowledge the financial support from the National Natural Science Foundation of China (51704111 and 51374003) and a project supported by Scientific Research Fund of Hunan Provincial Education Department (18A187 and 18C0328).

\section{References}

[1] A. Liu, J. Huang, Z. Li et al., "Numerical simulation and experiment on the law of urban natural gas leakage and diffusion for different building layouts," Journal of Natural Gas Science and Engineering, vol. 54, pp. 1-10, 2018.

[2] Y. Zhao, L. Xihong, and L. Jianbo, "Analysis on the diffusion hazards of dynamic leakage of gas pipeline," Reliability Engineering \& System Safety, vol. 92, no. 1, pp. 47-53, 2007.

[3] A. Ebrahimi-Moghadam, M. Farzaneh-Gord, A. Arabkoohsar, and A. J. Moghadam, "CFD analysis of natural gas emission from damaged pipelines: correlation development for leakage estimation," Journal of Cleaner Production, vol. 199, pp. 257-271, 2018.

[4] R. Moloudi and J. Abolfazli Esfahani, "Modeling of gas release following pipeline rupture: proposing non-dimensional correlation," Journal of Loss Prevention in the Process Industries, vol. 32, pp. 207-217, 2014.

[5] M. Cheng, M. Wu, L. Zhao, and M. Yang, "Numerical simulation of urban buried gas pipeline leakage and diffusion," Chemical Engineering of Oil \& Gas, vol. 43, no. 1, pp. 94-98, 2014, (in Chinese).

[6] L. Xinhong, C. Guoming, Z. Renren, Z. Hongwei, and F. Jianmin, "Simulation and assessment of underwater gas release and dispersion from subsea gas pipelines leak," Process Safety and Environmental Protection, vol. 119, pp. 46-57, 2018.

[7] M. Mirzaei, M. Najafi, and H. Niasari, "Experimental and numerical analysis of dynamic rupture of steel pipes under internal high-speed moving pressures," International Journal of Impact Engineering, vol. 85, pp. 27-36, 2015.

[8] EGIG and European Gas pipeline Incident Data Group, Gas Pipeline Incidents, 10th Report of the European Gas Pipeline Incident Data Group (Period 1970-2016), EGIG, European Gas pipeline Incident Data Group, New York, NY, USA, 2018.

[9] P. F. Liu, J. Y. Zheng, B. J. Zhang, and P. Shi, "Failure analysis of natural gas buried X65 steel pipeline under deflection load using finite element method," Materials \& Design, vol. 31, no. 3, pp. 1384-1391, 2010.

[10] T. Xu, A. Yao, H. Jiang, Y. Li, and X. Zeng, "Dynamic response of buried gas pipeline under excavator loading: experimental/ numerical study," Engineering Failure Analysis, vol. 89, pp. 57-73, 2018.

[11] M. Li and B. Yang, "Finite element analysis of buried polyethylene gas pipeline near impact-loading zone," China Plastic, vol. 8, pp. 86-91, 2018, (in Chinese).

[12] X. Liu, H. Zhang, M. Xia et al., "Mechanical response of buried polyethylene pipelines under excavation load during pavement construction," Engineering Failure Analysis, vol. 90, pp. 355-370, 2018.

[13] C. Cui, S. H. Shao, and X. Zhang, "Experimental study on gas explosion suppression by coupling $\mathrm{CO} 2$ to a vacuum chamber," Powder Technology, vol. 335, pp. 42-53, 2018.

[14] J. Zhang, L. Zhang, and Z. Liang, "Buckling failure of a buried pipeline subjected to ground explosions," Powder Technology, vol. 114, pp. 36-47, 2017.

[15] M. Mokhtari and A. Alavi Nia, "A parametric study on the mechanical performance of buried X65 steel pipelines under subsurface detonation," Archives of Civil and Mechanical Engineering, vol. 15, no. 3, pp. 668-679, 2015.

[16] Y.-G. Wang, C. C. Liao, J.-H. Wang, and D.-S. Jeng, "Dynamic response of pipelines with various burial depth due to underwater explosion," Ocean Engineering, vol. 164, pp. 114-126, 2018.

[17] B. Bang, H.-S. Park, J.-H. Kim, S. S. Al-Deyab, A. L. Yarin, and S. S. Yoon, "Simplified method for estimating the effect of a hydrogen explosion on a nearby pipeline," Journal of Loss Prevention in the Process Industries, vol. 40, pp. 112-116, 2016.

[18] J. G. Ramírez-Camacho, F. Carbone, E. Pastor, R. Bubbico, and J. Casal, "Assessing the consequences of pipeline accidents to support land-use planning," Safety Science, vol. 97, pp. 34-42, 2017.

[19] H. Zhian, L. Zhigang, C. Shengguo, Z. Yansong, and Z. Yinghua, "Numerical simulation and study on the transmission law of flame and pressure wave of pipeline gas explosion," Safety Science, vol. 50, no. 4, pp. 806-810, 2012.

[20] Q. Ye, G. G. X. Wang, Z. Jia, and C. Zheng, "Experimental study on the influence of wall heat effect on gas explosion and its propagation," Applied Thermal Engineering, vol. 118, pp. 392-397, 2017. 
[21] P. G. Cirimello, J. L. Otegui, and L. M. Buisel, "Explosion in gas pipeline: witnesses' perceptions and expert analyses' results," Engineering Failure Analysis, vol. 106, p. 104142, 2019.

[22] K. Wang, T. Shi, Y. He, M. Li, and X. Qian, "Case analysis and CFD numerical study on gas explosion and damage processing caused by aging urban subsurface pipeline failures," Engineering Failure Analysis, vol. 97, pp. 201-219, 2019.

[23] R. Li, R. Si, K. Gao, X. Qin, and L. Wen, "Experimental study on the effect of explosion suppression in low-concentration gas transportation," Journal of Loss Prevention in the Process Industries, vol. 54, pp. 216-221, 2018.

[24] B. Nie, X. He, R. Zhang, W. Chen, and J. Zhang, "The roles of foam ceramics in suppression of gas explosion overpressure and quenching of flame propagation," Journal of Hazardous Materials, vol. 192, no. 2, pp. 741-747, 2011.

[25] Y. Guo, C. Liu, D. Wang et al., "Numerical study and safety spacing of buried parallel gas pipelines: a study based on TNT equivalent method," Journal of Hazardous Materials, vol. 168, 2018.

[26] D. Wang, "Safe distance of overhead parallel pipeline calculated by nemerical simulation of gas pipeline explosion," Journal of China University of Petroleum (Edition of Natural Science), vol. 5, pp. 175-180, 2013, (in Chinese).

[27] X. Wen, A. L. Yao, and T. L. Xu, "Analysis on impact effect of gas pipeline explosion to adjacent pipeline for parallel pipeline in tunnel," Journal of Safety Science and Technology, vol. 1, pp. 156-162, 2017, (in chinese).

[28] Y. Du, F. Zhou, L. Ma, J. Zheng, C. Xu, and G. Chen, "Consequence analysis of premixed flammable gas explosion occurring in pipe using a coupled fluid-structure-fracture approach," Journal of Loss Prevention in the Process Industries, vol. 57, pp. 81-93, 2019.

[29] P. Russo and F. Parisi, "Risk-targeted safety distance of reinforced concrete buildings from natural-gas transmission pipelines," Reliability Engineering \& System Safety, vol. 148, pp. 57-66, 2016.

[30] D. Wang, X. Qian, M. Yuan, T. Ji, W. Xu, and S. Liu, "Numerical simulation analysis of explosion process and destructive effect by gas explosion accident in buildings," Journal of Loss Prevention in the Process Industries, vol. 49, pp. 215-227, 2017.

[31] S. Sklavounos and F. Rigas, "Estimation of safety distances in the vicinity of fuel gas pipelines," Journal of Loss Prevention in the Process Industries, vol. 19, no. 1, pp. 24-31, 2006.

[32] R. Khademi-Zahedi, "Application of the finite element method for evaluating the stress distribution in buried damaged polyethylene gas pipes," Underground Space, vol. 4, no. 1, pp. 59-71, 2019.

[33] R. Hassani and R. Basirat, "A 3D numerical modeling of polyethylene buried pipes affected by fault movement," Engineering Science and Technology, an International Journal, vol. 22, no. 2, pp. 482-488, 2019.

[34] O. Pennetier, M. William-Louis, and A. Langlet, "Numerical and reduced-scale experimental investigation of blast wave shape in underground transportation infrastructure," Process Safety and Environmental Protection, vol. 94, pp. 96-104, 2015.

[35] L. Luo, Y. Ma, and Y. Zhang, "Numerical simulation of strenth failure of buried polyethylene pipes under foundation settlement," Journal of Building Materials, vol. 2, pp. 1-11, 2019, (in chinese).

[36] L. Pengfei, S. Hao, J. Shuguang et al., "Experimental study on the inhibitory effects and mechanisms of crystalliferous water- containing mineral salts," Combustion Science and Technology, vol. 191, no. 1-3, pp. 403-418, 2019.

[37] H. Shao, S. Q. Lu, and S. Jiang, "Effect of frequency conversion ventilation on coal spontaneous combustion," Combustion Science and Technology, vol. 191, no. 3, pp. 1-16, 2020.

[38] D. Zhong, Z. Lu, X. Huang, and Z. Lu, "Experimental study on buried PE pipeline under blasting loads," Blasting, vol. 35, no. 4, pp. 1-5, 2018, (in Chinese).

[39] S. Peng, Q. Chen, C. Zheng et al., "Analysis of particle deposition in a new-type rectifying plate system during shale gas extraction," Energy Ence \& Engineering, vol. 8, no. 3, 2020.

[40] E. Liu, W. Li, H. Cai et al., "Formation mechanism of trailing oil in product oil pipeline," Processes, vol. 7, no. 1, 2018.

[41] Z. Su, E. Liu, Y. Xu et al., "Flow field and noise characteristics of manifold in natural gas transportation station," Oil \& Gas Ence and Technology, vol. 74, no. 1, pp. 1-10, 2019.

[42] J. Zhang, H. Zhang, L. Zhang et al., "Buckling response analysis of buried steel pipe under multiple explosive loadings," Journal of Pipeline Systems Engineering and Practice, vol. 11, no. 2, 2020.

[43] J. Zhang and J. Xie, "Effect of reservoir's permeability and porosity on the performance of cellular development model for enhanced geothermal system," Renewable Energy, vol. 148, pp. 824-838, 2020. 